\title{
Bioadhesion in the oral cavity and approaches for biofilm management by surface modifications
}

\author{
Torsten Sterzenbach $^{1}$ (D) $\cdot$ Ralf Helbig ${ }^{2} \cdot$ Christian Hannig $^{1} \cdot$ Matthias Hannig $^{3}$
}

Received: 11 March 2020 / Accepted: 15 October 2020 / Published online: 27 October 2020

(C) The Author(s) 2020

\begin{abstract}
Background All soft and solid surface structures in the oral cavity are covered by the acquired pellicle followed by bacterial colonization. This applies for natural structures as well as for restorative or prosthetic materials; the adherent bacterial biofilm is associated among others with the development of caries, periodontal diseases, peri-implantitis, or denture-associated stomatitis. Accordingly, there is a considerable demand for novel materials and coatings that limit and modulate bacterial attachment and/or propagation of microorganisms.

Objectives and findings The present paper depicts the current knowledge on the impact of different physicochemical surface characteristics on bioadsorption in the oral cavity. Furthermore, it was carved out which strategies were developed in dental research and general surface science to inhibit bacterial colonization and to delay biofilm formation by low-fouling or "easy-toclean" surfaces. These include the modulation of physicochemical properties such as periodic topographies, roughness, surface free energy, or hardness. In recent years, a large emphasis was laid on micro- and nanostructured surfaces and on liquid repellent superhydrophic as well as superhydrophilic interfaces. Materials incorporating mobile or bound nanoparticles promoting bacteriostatic or bacteriotoxic properties were also used. Recently, chemically textured interfaces gained increasing interest and could represent promising solutions for innovative antibioadhesion interfaces. Due to the unique conditions in the oral cavity, mainly in vivo or in situ studies were considered in the review.

Conclusion Despite many promising approaches for modulation of biofilm formation in the oral cavity, the ubiquitous phenomenon of bioadsorption and adhesion pellicle formation in the challenging oral milieu masks surface properties and therewith hampers low-fouling strategies.

Clinical relevance Improved dental materials and surface coatings with easy-to-clean properties have the potential to improve oral health, but extensive and systematic research is required in this field to develop biocompatible and effective substances.
\end{abstract}

Keywords Oral biofilms $\cdot$ Biofilm management $\cdot$ Low-fouling surfaces $\cdot$ Nanostructured surfaces $\cdot$ Textured surfaces $\cdot$ Pellicle

Torsten Sterzenbach

torsten.sterzenbach@uniklinikum-dresden.de

1 Clinic of Operative and Pediatric Dentistry, Medical Faculty Carl Gustav Carus, Technische Universität Dresden, Fetscherstraße 74, 01307 Dresden, Germany

2 Max Bergmann Center of Biomaterials, Leibniz-Institut für Polymerforschung Dresden e.V., Hohe Straße 6, 01069 Dresden, Germany

3 Clinic of Operative Dentistry, Periodontology and Preventive Dentistry, University Hospital, Saarland University, Building 73, 66421 Homburg/Saar, Germany

\section{The oral microbiota in health and disease}

The oral bacterial community consists of more than 1000 different bacterial species and an estimated number of around 20 billion residents [1]. Most of them $(\approx 96 \%)$ belong to the phyla of Firmicutes, Actinobacteria, Proteobacteria, Fusobacteria, Bacteroidetes, and Spirochaetes [2, 3]. Many of them are capable of colonizing both nonshedding surfaces of teeth (enamel or dentin) as well as epithelial mucosal surfaces. There they can form biofilms (plaque), which are highly variable in their composition depending on the specific surface, the particular location within the oral cavity, and the overall oral health status of the individual subjects, but also on environmental conditions like carbohydrate intake or flow of gingival crevicular fluid $[4,5]$. Within healthy individuals, the 
host and microbial communities generally live in a homeostatic balance, and the oral microbiota serves many beneficial functions to the host. For example, it provides colonization resistance toward the settlement by pathogenic microorganisms [6]. Colonization resistance is mediated by several factors like competition for substrates, generating an inhibitory microenvironment for settlement of pathogens, release of antibactericidal substances, and stimulation of the host immune system (recently reviewed in [7]). However, many factors can disrupt this fragile equilibrium. This results in an imbalance (dysbiosis) of the microbiota ultimately leading to selection and enrichment of pathobionts [8]; for example, poor oral hygiene but also inflammatory and autoimmune diseases, immunodeficiency disorders, diet rich in low molecular carbohydrates, and many more health issues can disturb a healthy oral microbiota (recently reviewed in [9]). The breakdown of carbohydrates by Streptococcus mutans and other microbial pathogens can lead to an acidification of tooth surfaces. This may result in cavities due to demineralization and dissolving hard tissues of the teeth [10]. The onset of inflammation leads to the development of gingivitis [11]. This is caused by biofilm formation at the gingival margin. Colonization and inflammation of the subgingival pocket and the gingival crevice does not necessarily lead to the development of periodontitis, but rather to a change in environmental conditions, followed by an ecological shift toward Gram-negative and proteolytic bacteria that trigger immunological reactions that can lead to the clinical signs of periodontitis [12, 13]. Unlike gastrointestinal disorders, the onset of periodontitis is characterized by an increase in microbial diversity $[14,15]$. However, most oral diseases are not caused by isolated infections with specific pathogens but are rather an intrinsic interplay between the host, keystone pathogens, and polymicrobial synergy and dysbiosis (PSD) $[16,17]$. Nevertheless, a myriad of species have been connected to periodontal diseases, with the most frequent ones being Fusobacterium nucleatum, Aggregatibacter actinomycetemcomitans, Prevotella intermedia, Porphyromonas gingivalis, or Tannerella forsythia $[18,19]$.

However, the oral microbiota and related biofilm development do not only pose a major health issue on natural dental or soft tissue but also on artificial dental materials (e.g., resin-based composite fillings, crowns, dentures, or implants). This may lead to inflammation and destruction of soft and hard tissues surrounding dental implants. These conditions can develop into mucositis and peri-implantitis similar to gingivitis and periodontitis [20]. Also biofilm formation at the margins of dental restorations can lead to secondary caries [21]. Therefore, the development of artificial dental materials with reduced bacterial colonization or "easy-to-clean" properties is of outstanding importance for oral health. In this article, we will present and discuss the background as well as current and potential new strategies for the management of biofilm formation in the oral cavity based on surface modifications.

\section{Physicochemical basics of adhesion and adsorption}

Attachment of proteins or microorganisms to surfaces is a multifaceted process and is mediated by a plethora of physical and chemical interactions. In the following chapter, we will present a brief overview of the processes involved in adhesion of both proteins and microorganisms to surfaces in general.

\section{Attachment of proteins to surfaces}

In general, the Langmuir and the RSA (random sequential adsorption) model originally described basic protein adsorption to surfaces (Fig. 1a) [22]. Both models in its basic form cover adsorption of proteins in aqueous solutions to solid surfaces and assume that adsorption is reversible. In the Langmuir model, it is furthermore assumed that adsorbed molecules do not interact with each other, while the RSA model describes the probability of a new particle adsorbing to a surface in the presence of previously adsorbed particles. The Langmuir model then predicts the change of surface coverage over time as $\frac{\mathrm{d} \theta}{\mathrm{d} t}=k_{\mathrm{a}} C_{\mathrm{b}}(1-\theta)-k_{\mathrm{d}} \theta$, where $\theta$ is the surface coverage, $k_{\mathrm{a}}$ and $k_{\mathrm{d}}$ are the adsorption and desorption constants, and $C_{\mathrm{b}}$ is the bulk concentration of the adsorbing molecule. The actual surface concentration $\Gamma$ is then calculated as $\dot{\Gamma}=\dot{\Gamma}_{\max } \theta=\dot{\Gamma}_{\max } \frac{K C_{\mathrm{b}}}{1+K C_{\mathrm{b}}}$, with $K$ being the associated equilibrium constant [23]. In the RSA model, a function $\Phi(\theta)$ is added which describes the probability function that new particles can adsorb in the presence of previously adsorbed particles [24]. This can then be described as $\frac{\mathrm{d} \theta}{\mathrm{d} t}=k_{\mathrm{a}}$ $C_{\mathrm{b}} \Phi(\theta)-k_{\mathrm{d}} \theta$. In reality, the situation becomes more complex since proteins can either be loosely, interchangeably, or irreversibly bound to substrate surfaces (Fig. 1b). This is often accompanied by conformational changes of these proteins. Often, these conformational changes are accompanied by alterations in properties like, e.g., enzymatic or adhesive activities [25-28]. We will not go into details for these models in the context of this article, but they were recently nicely reviewed by Kim [22] and Sanfeld et al. [29].

In competitive adsorption situations with multicomponent solutions, it becomes more complex since various proteins will be present with different concentrations and different adsorption and desorption constants to surfaces. More abundant proteins will adsorb to surfaces first but can be replaced by less abundant ones with higher adsorption affinity. This can lead to sequential absorbance maximums of different proteins over time until an equilibrium is reached (Vroman effect) [30, 31]. Furthermore, in multicomponent solutions, proteinprotein interactions will lead to the formation of homo- or heteromeric complexes [32].

External factors that modulate adherence to surfaces are especially the $\mathrm{pH}$ and ionic strength of the surrounding 
Fig. 1 Interaction and adsorption of proteins to surfaces. a

Illustration of the Langmuir and RSA (random sequential adsorption) models ( $k_{\mathrm{a}}$ adsorption constant, $k_{\mathrm{d}}$ desorption constant). b Depending on the state and properties, proteins can loosely, interchangeably, or irreversibly attach to surfaces. c Factors that influence protein adsorption are, among others, properties of the protein(s), $\mathrm{pH}$ of the surrounding medium, and surface properties like surface charge, surface energy, or topography a

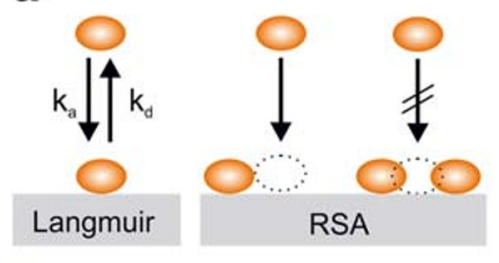

b

C

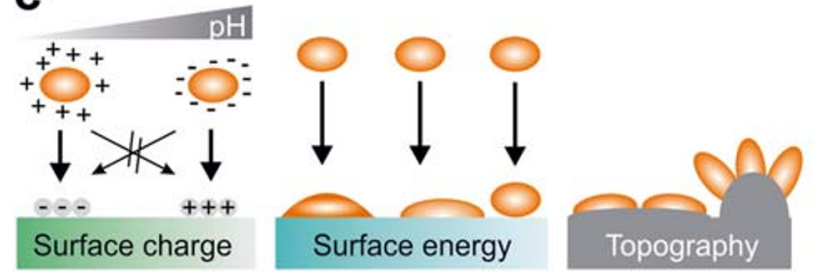

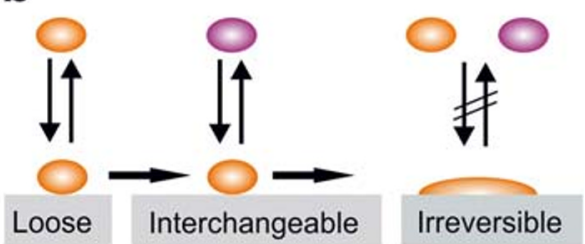

rreversible medium. Around the isoelectric point, electrostatic proteinprotein repulsions are minimized. At $\mathrm{pH}$ values higher or lower than the isoelectric point, migration of proteins toward charged surfaces is maximized in the case of opposite charges and minimized in the case of similar charges between proteins and surfaces (Fig. 1c) [33]. High ionic strength also reduces electrostatic interactions between charged sites and increases the likelihood of protein aggregation because of surface charge neutralization [34].

Furthermore, the properties of the surface modulate adhesive behaviors of proteins (Fig. 1c). Factors that modify adsorption are among others surface free energy, charge, polarity, or morphology. In general, proteins tend to adhere stronger to surfaces with higher surface energy, to charged surfaces, and to nonpolar surfaces [35]. Although most proteins adhere better to slightly hydrophobic compared with hydrophilic surfaces, superhydrophobic surfaces generally yield reduced protein adsorption [36]. Depending on the properties of the protein and surface, adsorption of proteins is often also accompanied by orientational and conformational changes that can influence the properties of the protein $[37,38]$.

\section{Initial attachment of microorganisms to surfaces}

The process of microbial adhesion can be divided into different steps: transport of the microorganisms to the surface, reversible adhesion to the surface, transition to irreversible adhesion, and emerging biofilm formation. Under flow chamber conditions, the initial transport of bacteria to surfaces is governed by the theoretical deposition rate according to the Smoluchowski-Levich (SL) approximation: $j_{0}^{\prime}=0.538 \frac{D \infty C}{r}\left(\frac{h \mathrm{Pe}}{x}\right) 1 / 3$, where $D_{\infty}$ is the bacterial diffusion coefficient, $C$ is the bacterial concentration, $\mathrm{Pe}$ is the ratio between convection and diffusion, $r$ is the hydrodynamic radius of the bacterium, and $x$ is the distance from the inlet of the flow displacement system [39]. It should be noted that the contribution of gravity and interactions between depositing bacteria and the substrate surface is neglected in this equation. Real deposition rates are vastly influenced by factors like surface charge, motility, and surface coverage.

Nonspecific forces involved in reversible attachment of bacteria to surfaces can be grouped into short to medium (e.g., surface free energy, hydrophobic and dipole-dipole interactions, hydrogen, and covalent bonds) and long range forces (van der Waals forces and Coulomb interactions). Importantly, surfaces in the oral cavity are additionally covered by the acquired pellicle, which modulates surfaces and offers receptors, i.e., specific binding sites, but also counteracts adhesion by antimicrobial activities as discussed later ("The acquired oral pellicle" section). In addition, strong shear forces in the oral environment influence adhesion [40] (Fig. 2).

Classically, bacterial attachment to surfaces is explained by the DLVO (Derjaguin-Landau-Verwey-Overbeek) or the extended DLVO (XDLVO) theory (reviewed in [41, 42]). In short, in the extended DLVO theory, total interaction forces between bacteria and substrates $\left(F_{\text {total }}\right)$ are calculated as the sum of Lifshitz-van der Waals $\left(F_{\mathrm{LW}}\right)$ forces, electrostatic interaction forces $\left(F_{\mathrm{EL}}\right)$, and acid-base interaction $\left(F_{\mathrm{AB}}\right)$ forces, which can be either attractive or repulsive (Fig. 3a). When plotting the sum of these forces to the distance between bacteria and surface, in very close proximity, forces will have a deep minimum and a secondary interaction minimum at a distance of $20-50 \mathrm{~nm}$. But between these minima, forces will be strongly repellent leading to an energy barrier preventing attachment (Fig. 3b). Pure Brownian motion cannot generally pass this energy barrier so that bacteria remain trapped in the secondary minimum. In the original theory, bacteria were treated as colloidal round spheres, ignoring surface roughness of bacteria and surface appendages attached to the bacterial membrane (e.g., pili, fimbriae, flagella). It was suggested that surface appendages have a high probability to pierce through the energy barrier and thereby tether a bacterium to the surface 
Fig. 2 Interactions influencing bioadhesion and biofilm formation in the oral cavity. Different short, medium, and long range forces influence adhesion of bacteria to surfaces. The pellicle masks some of these properties while also providing new ones. Providing receptors and metabolic substrates promote, while shear forces and antimicrobial activities counteract bacterial adhesion and biofilm formation (modified according to Hannig et al. [41])

\section{Long range forces:}

- van der Waals forces

- Coulomb interactions
Short and medium range forces:

- surface free energy

- hydrophobic interactions

- hydrogen bonds

- covalent bonds

- dipole-dipole interactions

\section{Pellicle formation:}

- partial masking of substrate identity - modulation of new biological identity of adsorbed biomolecules

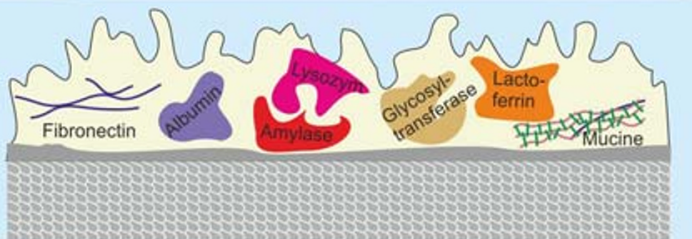

Counteracting:

- anti-microbial activities

- shear forces

\section{Promoting:}

- receptors

- metabolic substrates
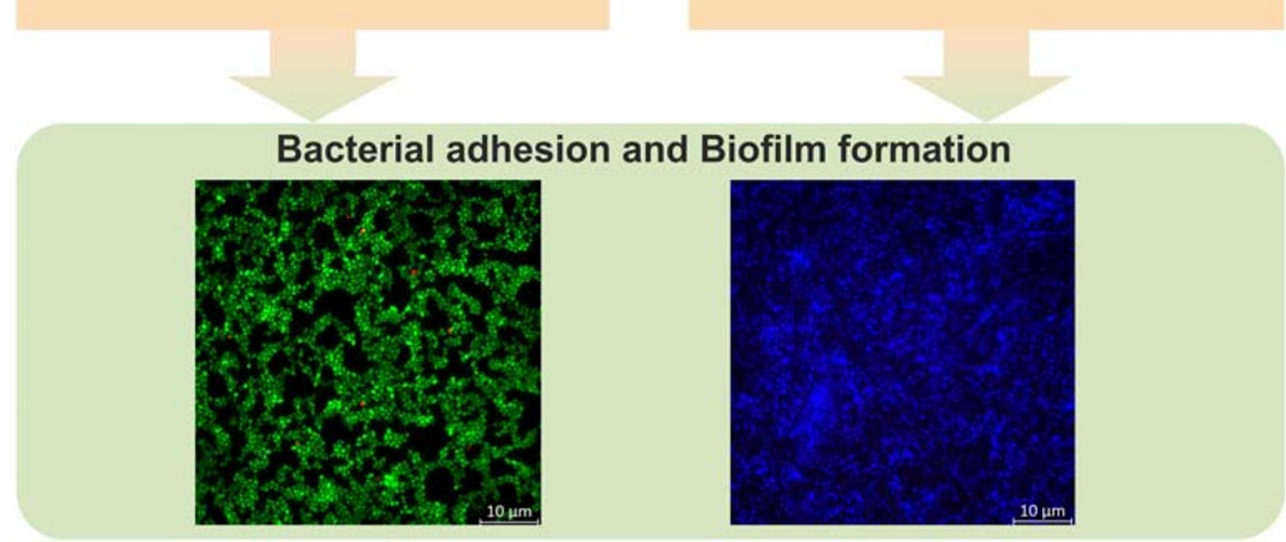

$[43,45]$. At this stage, a firm anchorage between the bacterium and the surface can be established involving covalent, ionic, or hydrogen bonding [44] (Fig. 3c). In this respect, it is important to note that adhesive strength is not mainly determined by contact area but rather by the amount and nature of contacts between surfaces and macromolecules on the bacterial surface $[46,47]$. Recently, it was proposed that irreversible bacterial adhesion is the result of a multitude of reversible binding tethers that continuously detach and re-attach. Tight adhesion is achieved since these events do not happen simultaneously. Because these events do not occur at the same position, they lead to nanoscopic displacement of a bacterium thereby repositioning the bacteria on very small scales [48].

Bacteria that are in direct contact with a surface are subjected to cell wall deformation due to adhesion forces [49]. This leads to an increase in contact area and triggers differential gene expression in bacteria in close proximity to the surface [50]. These initial colonizers then signal to nearby bacteria by quorum sensing to trigger the switch from a planktonic to a biofilm stage in a larger population $[51,52]$. Finally, also hydrodynamics and shear stress modulate adhesion of microorganisms to surfaces $[53,54]$.

\section{Influence of physicochemical properties on adhesion}

Bacteria tend to adhere best to slightly hydrophobic or hydrophilic surfaces, while strongly hydrophobic or hydrophilic surfaces generally lead to reduced adhesion (will be discussed later). Surface hydrophobicity or hydrophilicity correlates to surface wettability, which is often expressed by the contact angle (CA) of a water droplet on the substrate. Basically, the intrinsic $\mathrm{CA}$ at the boundary of the three phases (substrate, water, air) can be described by the Young's equation $\cos \left(\theta_{Y}\right)$ $=\frac{\gamma \mathrm{SV}-\gamma \mathrm{SL}}{\gamma \mathrm{LV}}$, where $\gamma^{\mathrm{SL}}, \gamma^{\mathrm{SV}}$, and $\gamma^{\mathrm{LV}}$ are the solid-liquid, solid-vapor, and liquid-vapor interfacial energies, respectively. The liquid-vapor interfacial energy is often referred to as surface tension of the liquid. Hydrophobic surfaces have an intrinsic CA greater than $90^{\circ}$ and hydrophilic surfaces smaller than $90^{\circ}$ (Fig. 4a). 


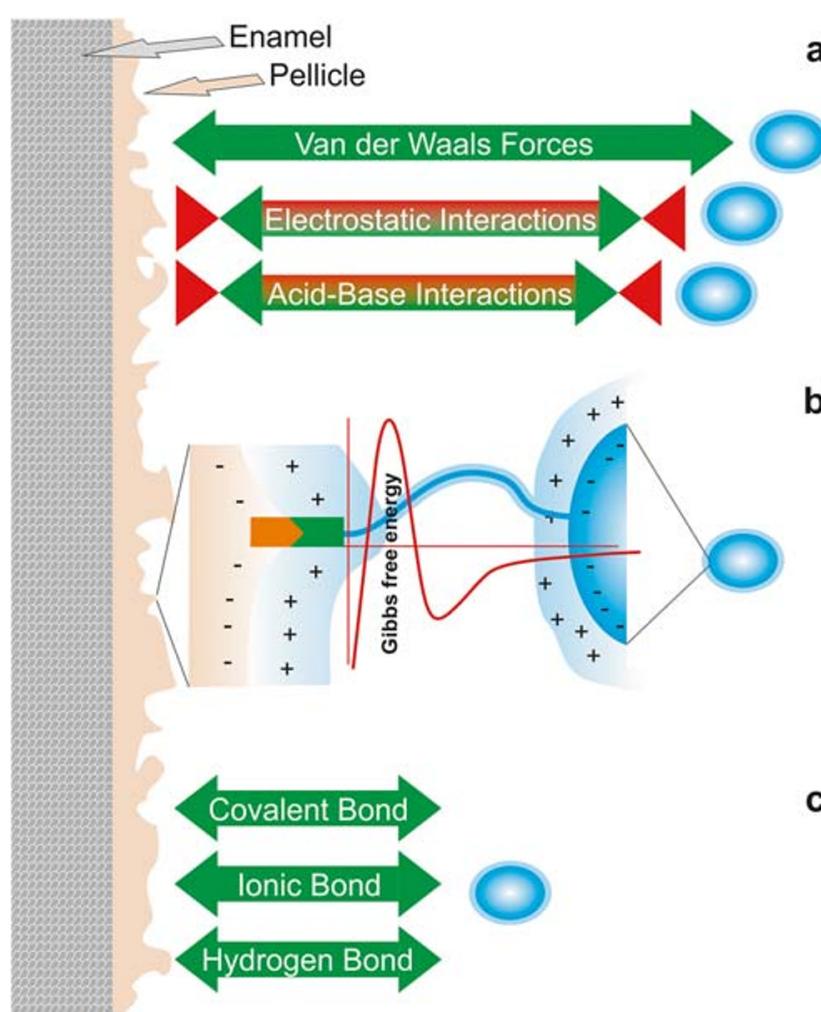

Fig. 3 Initial bacterial adhesion to a pellicle-coated surface. a Initial bacterial approach and adhesion to surfaces is mediated by both attractive (green) and repulsive (red) short and long range forces [41]. b Depicted is the Stern layer surrounding the pellicle-coated surface and bacteria and the Gibbs free energy resulting from the sum of different forces (red curve) in relation to the distance between a bacterium and the surface. Small structures like fimbriae or flagella can overcome repulsive forces [43]. c The establishment of covalent, ionic, and hydrogen bonds establishes firm bonds between bacteria and the surface [44]

In the intrinsic or actual CA, $\theta_{Y}$ is barely observable. One reason is that real surfaces are not completely flat. Therefore, the measured CA on real substrates can dramatically differ from $\theta_{Y}$, especially on very rough or textured surfaces. The Wenzel model [55] clarifies this behavior with a roughness value $r$, which is the ratio of actual and apparent surface area in a relation of the apparent (measured) CA $\left(\theta^{*}\right)$, and the (actual) intrinsic $\mathrm{CA}\left(\theta_{Y}\right)$, defined by the Young's equation, $\cos \left(\theta^{*}\right)=r \cos \left(\theta_{Y}\right)$. Indeed, roughening of a surface can be considered as amplification of surface chemistry, i.e., it increases the CA of a water droplet on intrinsically hydrophobic surfaces and decreases it on intrinsically hydrophilic surfaces $[56,57]$.

So far, this scenario describes the wetting of chemically homogeneous substrates. Cassie and Baxter [58] extended this model for a droplet sitting on a multiphasic surface by $\cos \left(\theta^{*}\right)=f_{1} \cos \left(\theta_{Y 1}\right)+f_{2} \cos \left(\theta_{Y 2}\right)+f_{i} \cos \left(\theta_{Y i}\right)$, whereby $f_{i}$ is the fraction of the different chemical phases, with $\sum_{i} f_{i}=1$, and $\theta_{Y i}$ being the respective intrinsic contact angles. One special case for very rough hydrophobic surfaces on which droplets can sit onto a so-called solid-air composite became very famous under the name superhydrophobicity. Here, the surface is only partially wetted (Cassie state) - in opposite to full wetting (Wenzel state) - and air is trapped in the surface cavities (Fig. 4b). This can be modeled by a droplet sitting on two phases, which can be described by $\cos \left(\theta^{*}\right)=f_{1} \cos \left(\theta_{Y}\right)+f_{2}$ $\cos \left(\theta_{\text {Air }}=180^{\circ}\right)=f_{1} \cos \left(\theta_{\mathrm{Y}}\right)-f_{2}$ where $f_{1}$ and $f_{2}$ are the area fractions of solid and air under a drop on the substrate [59]. This wetting state is accompanied by very high CA $\left(>150^{\circ}\right)$ and a highly repellent character, which can be defined by a critical tilt angle of the surface when the droplet starts to roll off $\left(<5^{\circ}\right)$ (Fig. 4c). The low roll-off angle and the small topmost contact area on the rough surface reduce the temporal window and spatial possibilities for bioadhesion events for bacteria from a contaminated droplet. Furthermore, when immersed, the formation of the liquid-air interface between solid

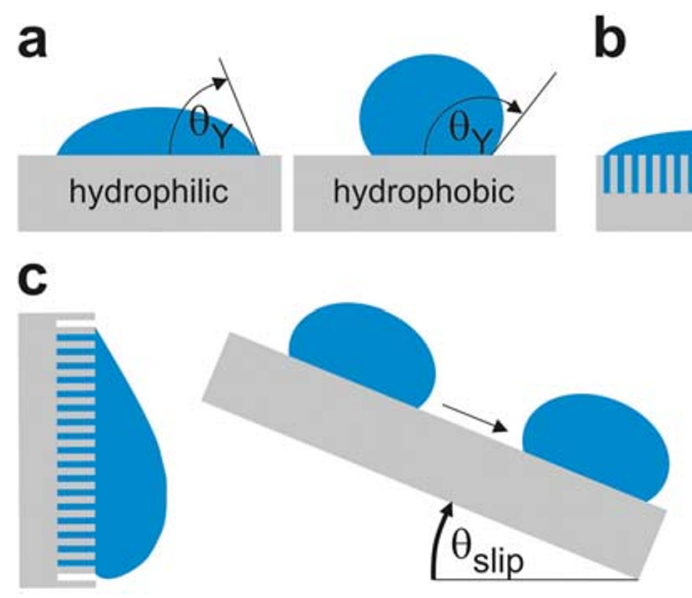

Fig. 4 Interaction of water with different surfaces. a Water contact angles on different surfaces. Contact angles on hydrophilic surfaces are below $90^{\circ}$, while hydrophobic surfaces have contact angles of more than $90^{\circ}$. b Depiction of Wenzel and Cassie-Baxter wetting regimes. In the Wenzel state, cavities are fully wetted, while in the Cassie-Baxter state, air is

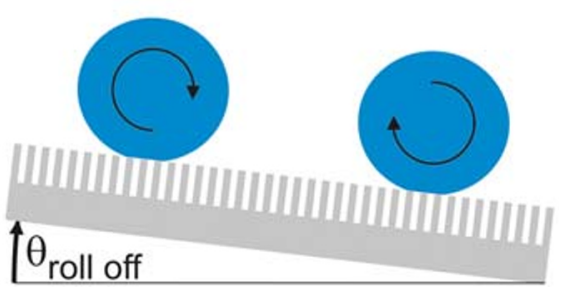

trapped within cavities. c Water roll-off angles on hydrophilic and superhydrophobic surfaces. Hydrophilic surfaces possess relatively high roll-off angles, while superhydrophobic surfaces have roll-off angles of less than $5^{\circ}$ 
and liquid yields a protective layer, which is almost impossible to penetrate by bacteria and their appendages (fimbria, flagella). This prevents the settlement of microorganisms on the substrate and inhibits initial microbial adhesion.

\section{Bioadhesion in the oral cavity}

\section{The acquired oral pellicle}

Both soft (mucosal) and hard (enamel and dentine) tissues in the oral cavity are covered by the acquired oral pellicle within minutes (in more detail reviewed in [41, 60] (Fig. 5a). Almost instantaneously, an electron-dense pellicle layer is formed by adsorption of salivary proteins on the enamel surface [61, 62]. This is followed by a more continuous formation of a more complex globular layer [63]. The pellicle is mainly composed of selectively absorbed salivary proteins and peptides but also contains proteins and other macromolecules from gingival crevicular fluid, blood, bacteria, mucosa, and diet [62, 64-66]. Despite a large variability in individuals' profiles, a core set of 68 proteins present in the pellicle proteome of 24 individuals was identified including among others antibacterial proteins (e.g., lysozyme, lactotransferrin, lactoperoxidase, and cystatins), lubricants (e.g., mucin 7), proteins promoting protein-substrate interactions (e.g., S100 family members, annexin A1, or elongation factor 2) or protein-protein interactions (e.g., 14-3-3 protein family or gammaglutamyltransferase $\mathrm{E}$ ), and proteins promoting pellicle integrity (e.g., carbonic anhydrase 6) $[67,68]$. The pellicle provides many beneficial functions [61]. It serves as a lubricant and provides protection of the dental surface. It also serves as a protective layer against erosion by preventing decalcification
Fig. 5 Overview of the acquired oral pellicle and biofilm formation in the oral cavity. a Depicted is the acquired oral pellicle on enamel composed of a thin basal pellicle and on top of it granular and globular structures. Early colonizers first adhere to lectins and other receptors on the acquired proteinaceous oral pellicle via specific adhesins in order to adhere tightly. b More microorganisms integrate into the developing biofilm structure by duplication or coadherence of further bacteria. $\mathbf{c}$ Depiction of a fully developed biofilm in the oral cavity. A multispecies biofilm is embedded into an extracellular matrix consisting among others of proteins, lipids, extracellular DNA, exopolysaccharides, and amyloid structures
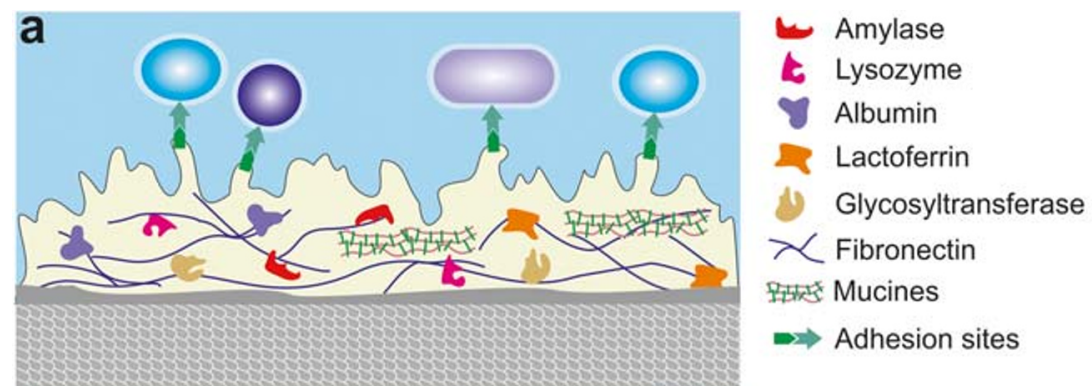

跳楼 Mucines
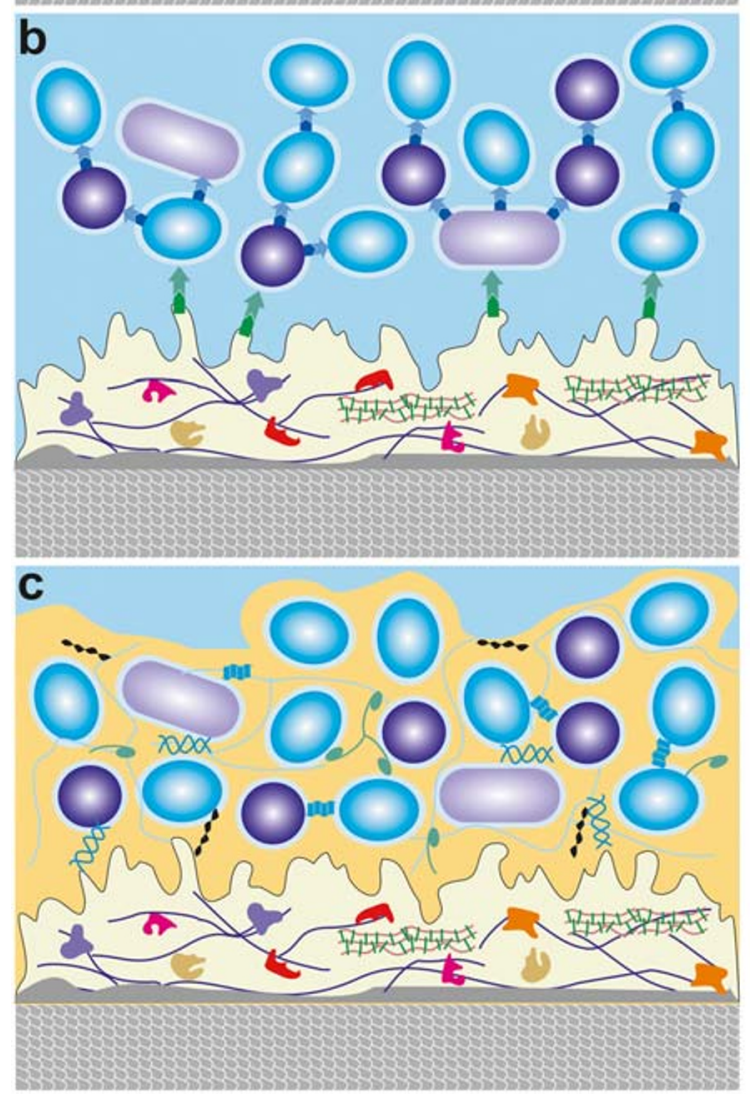

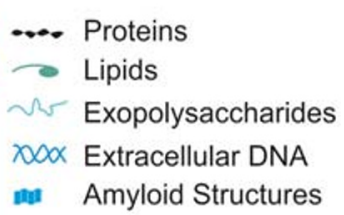


of hard tissue [60]. Finally, the acquired pellicle contains several antibacterial components, among them relatively high concentrations of lysozyme and peroxidases. At the same time, the acquired pellicle also consists of many components that are beneficial to the adherence of bacteria and, henceforth, biofilm formation [69]. Especially ligands for bacterial adhesins like glycolipids, fibrinogen, or collagen play a major role in this process. They serve as anchor points for the initial adhesion of pioneer organisms like different Streptococcus spp. or Actinomyces spp. [70, 71]. This leads to early phases of biofilm formation and by the interconnection with other species to the establishment of mature plaque (see next chapter). However, it is important to note that according to recent studies, the ultrastructure, enzyme activities, and proteomic profile of the acquired pellicle do not show major differences between otherwise healthy caries-active and inactive subjects $[67,72,73]$.

Furthermore, the oral pellicle affects the physicochemical properties of surfaces (e.g., surface roughness, hydrophobicity/hydrophilicity, wettability). For example, pellicle formation leads to significantly altered water contact angles on resinbased composites (concise, occlusin, heliomolar) compared with untreated samples [74]. In addition, pellicle formation can level out surface roughness [75-78].

This may lead to modification of bacterial adherence properties and degree of biofilm formation on natural and artificial surfaces in the oral cavity $[79,80]$.

\section{Oral biofilms}

When forming biofilms on oral nonshedding surfaces, bacteria first have to adhere to the pellicle-coated substrate (Fig. 5a). Specific adhesins generally mediate initial adhesion to these surfaces [41, 69]. Most bacteria possess a plethora of different adhesins that are grouped among others into fimbrial adhesins, pili, autotransported adhesins, or surface proteins, which vary strongly in their assembly mechanisms, structure, and appearance [81-83]. For example, many pathogenic oral bacteria possess adhesins binding to major components of the oral pellicle like agglutinin, amylase, fibrinogen, fibronectin, or mucins [84-88]. Furthermore, many bacteria possess collagen-binding proteins $[89,90]$. It is important to note that the composition of biofilms on natural surfaces within the oral cavity varies strongly depending on the localization (e.g., suband supragingival plaque vs. buccal or gingival mucosal biofilms) and between individuals [5].

Streptococci as well as Neisseria, Rothia, Actinomyces, or Veillonella are frequently found among others in the early stages of plaque formation, while after just $6 \mathrm{~h}$, more than 90 different species belonging to 40 genera and 7 phyla were detected in the in vivo supragingival oral dental biofilm [91] (Fig. 5b). Later on, secondary colonizers like Fusobacterium nucleatum, Treponema sp., Porphyromonas gingivalis, or
Aggregatibacter actinomycetemcomitans can be frequently found [92]. Furthermore, a complex extracellular matrix develops consisting of secreted proteins, lipids, exopolysaccharides, extracellular DNA, and amyloid structures $[4,93]$ (Fig. 5c). These microbial communities form an intrinsic network of co-existence and interspecies coaggregation [94]. Different species within the oral biofilm coregulate the expression of adherence factors as well as other virulence factors [4]. Furthermore, nutritional cross-feeding as well as co-ordinated metabolism of complex substrates takes place within biofilm communities (reviewed in [1]). In addition, bacteria in the oral environment also coregulate the expression of virulence factors (reviewed in [1]). For instance, biofilm formation and virulence gene expression of $S$. mutans is modulated by the presence of specific oral bacteria like Streptococcus oralis or Lactobacillus casei [95]. In addition, the surface can affect the transcriptional profile of bacteria [96]. Although the microbiota on mucosal sites strongly overlaps with the microbiota on nonshedding surfaces, several differences exist on the phylum, family, and genus levels. For example, buccal or keratinized mucosal surfaces show a high abundance of Streptococcus and Gemella spp., the tongue dorsum is characterized by Veillonella spp., and dental plaque has Corynebacteriaceae spp. as a biomarker [97, 98]. On the species level, for example, Streptococcus mitis has an exceptionally high abundance on keratinized gingiva, and for example, F. nucleatum or Actinomyces naeslundii are mainly found on the teeth, Fusobacterium periodonticum or Actinomyces graevenitzii on the tongue, and Fusobacterium sp. HMT248 or Haemophilus haemolyticus on keratinized gingiva $[5,99]$.

\section{Biofilms and pellicle formation on conventional dental materials}

Similar to natural oral substrates, restorative or prosthetic materials and devices like implants, dental fillings, or crowns are almost instantaneously covered by an acquired pellicle. Here, the pellicle also modulates the physicochemical properties of the materials [74-78]. Thereafter, as on natural dental structures, biofilms will be formed, which often lead to secondary caries, mucositis, or peri-implantitis and even the ultimate failure of these medical devices. This was reviewed in 2009 in [41]. In the following chapter, we will present a short summary and update on biofilm and pellicle formation on conventional dental materials.

\section{Biofilm formation on restorative materials}

A variety of different materials is routinely used for restoration and sealing of cavities as for example resin-based composite materials, amalgam, or glass ionomer cements as well as inlays, crowns, or fixed partial dentures made from gold alloys, 
ceramics, or cobalt chromium $(\mathrm{CoCr})$ alloys. However, the development of secondary caries due to biofilm formation on these materials and especially at the marginal gaps is the most common cause for their failure [100]. Amalgam-based materials have been mostly substituted in recent years by resin-based composite materials. However, besides the many advantages of resin-based composite materials, they more often lead to secondary caries compared with classic amalgambased materials [101, 102]. Unlike on resin-based composites, biofilms on amalgam surfaces consist of mostly nonviable bacteria probably due to the slow release of mercury and silver [103]. Additionally, dental resin-based composites tend to be more susceptible to decay due to acid produced by cariogenic bacteria [104]. However, it was also suggested that resinbased composite materials and amalgam do not show differences in biofilm formation or microbiota composition in a microcosm biofilm model, in situ or on freshly extracted teeth with secondary caries [105-108]. Also, biofilms developed on bovine enamel and on resin-based composites seem to differ only slightly in situ [109]. Glass ionomer cements have the ability to release fluorides over time in an acidified environment thereby offering protection from caries-promoting biofilm development and decreased acid production at least under in vitro conditions [110-112]. Biofilm formation by a mixture of salivary microorganisms was also reduced on glass ionomer cement materials compared with resin-based composite materials or amalgam [113]. In addition, in vitro and in situ glass ionomer cements seem to offer protection against demineralization $[106,114]$. Both in vitro and in situ biofilm formation on ceramics are mainly influenced by the composition and roughness of the used materials [115-117].

Polished gold alloys accumulated less bacteria compared with natural teeth in vivo although the composition of the biofilms was comparable [118]. In addition, biofilms accumulated on gold surfaces showed a low viability [119]. However, according to a 14-day in situ study, biofilm formation on gold, titanium, or zirconium abutment materials did not show major differences [120]. Also, biofilm formation over $48 \mathrm{~h}$ did not differ significantly between gold and ceramic bracket materials [121]. Studies on biofilm formation on $\mathrm{CoCr}$ alloys used in dentistry are inconclusive although at least under in vitro conditions biofilm formation seems to be in a similar range to titanium [122-124].

\section{Biofilm formation on dentures}

A large percentage of denture wearers are affected by dentureassociated stomatitis, which is mainly caused by Candida albicans [125], albeit also differences in denture-associated biofilms on the genus and species level of other microorganisms can be detected between patients affected by dentureassociated stomatitis and healthy subjects [126]. Dentures are mostly manufactured from polymethylmethacrylate (PMMA).
However, at least in vitro alternative materials like Molloplast B or Ufi-Gel showed lower colonization by C. albicans [127]. In addition, excess of cement for fixation of crowns favor the growth of periodontal microbiota [128], thereby cements on a zinc oxide eugenol basis seemed better suited than methacrylate cement for crowns cemented on implants $[129,130]$.

\section{Biofilm formation on implants}

Dental implants are generally made of titanium or zirconium. Areas of these dental abutments accessible to the oral microbiota are globally covered within a short time period with extensive biofilms after the lack of oral hygiene [131, 132]. This can lead to inflammatory lesions that may develop into peri-implant mucositis or peri-implantitis [20, 133]. Altered microbial communities characterize these infections. However, these altered communities can be quite different from the communities found in caries or gingivitis. The overall microbial diversity in peri-implantitis is lower compared with healthy teeth and is dominated by Gram-negative bacteria [134]. Species that generally cluster with peri-implantitis are among others $P$. gingivalis, $P$. intermedia, Treponema denticola, T. forsythia, and Fretibacterium fastidiosum [135-137]. However, the microbiota of biofilms formed on dental implants does not seem to differ between subjects with or without former periodontitis [132].

Some studies suggest that abutments made of zirconium generally accumulate less biofilm compared with titanium in vivo $[138,139]$ although other studies did not find differences between these two materials [140]. The composition of biofilm communities varied depending on implant materials in short-term (24 h) splint experiments [141, 142]. Furthermore, in a 6-month in vivo study, differences in the microbial community between titanium and zirconia implants could be detected [143]. Also, biofilm formation on titanium or zirconium abutments varies depending on surface modifications, roughness, and surface free energy although results are also often inconclusive [144]. In addition, it was suggested that titanium ions released due to degradation of implants' surfaces promote microbial dysbiosis as well as inflammatory processes around dental implants [145, 146].

\section{Pellicle formation on conventional dental materials}

To a large degree, biofilm formation on all these conventional dental materials is modulated by the formation of the acquired salivary pellicle formed on these materials as already outlined before. It was shown already around 20 years ago that the ultrastructural appearance of the in situ formed pellicle on enamel and various restorative materials like amalgam, ceramics, cements, resin-based composites, or titanium is very similar [65, 147]. In concordance with these findings, early plaque formation on these materials only showed minor, less 
pronounced variations. However, distinct differences were observed between buccally and lingually mounted test pieces [147]. Also at least under in vitro conditions, the composition of a pellicle formed on titanium or zirconium did not vary significantly in its protein content, while minor differences were found to pellicles formed on hydroxyl apatite [148]. Furthermore, amylase and lysozyme activity in the pellicle formed on different materials did not differ significantly in situ indicating similar biological activity of the pellicle on different dental materials [149, 150]. Nevertheless, in vitro adsorption kinetics of individual isolated salivary proteins varied between gold, titanium, and silica surfaces [151]. Also, different compositions of titanium modulated the composition of in vitro formed salivary pellicles [152]. In addition, roughening of titanium surfaces increased protein adsorption at least under in vitro conditions [77].

In summary, conventional dental materials still pose the problem of often extensive biofilm formation even under generally good oral conditions. This is caused by properties of the deployed materials that may promote bacterial attachment or the lack of anti-adhesive or antimicrobial properties. Furthermore, the acquired oral pellicle that forms on all these materials masks surface properties of these materials and, despite antibacterial properties, also provides anchor points for bacterial attachment. As a conclusion, there is a much-needed demand for novel improved materials in dentistry with increased low-fouling properties but that are otherwise fulfilling their role in the substitution of natural dental structures.

\section{Approaches for biofilm management in dental research}

As outlined before, conventional prosthetic and restorative materials as well as implants in the oral environment often pose the problem of extensive biofilm formation [120, 127, $128,132,153]$. This leads in many cases to the failure of the devices resulting in oral diseases like secondary caries, periodontitis, or peri-implantitis. Hence, many different kinds of strategies were developed to decrease adherence and/or biofilm formation on artificial dental surfaces. These include materials that modulate adherence of microorganisms as well as "easy-to-clean" surfaces that prevent tight attachment and allow easy removal of adhered microorganisms [154, 155]. Furthermore, concepts were developed that allow killing (bactericidal) or growth inhibition (bacteriostatic) of microorganisms upon surface contact. Strategies comprise modulation of surface architecture and topography as well as chemical or mechanical modification of surface structures. Chemical modulations were applied to change surface energy (hydrophobic vs. hydrophilic), or charge and mechanical properties were controlled by alternation of the intrinsic material elasticity. Often, different strategies are combined, such as mechanically or chemically modulated topographies or incorporation of functionalized nanoparticles into basic matrices. Many of these strategies offer the advantage that they can be implemented well in dental laboratories. Also, removable dentures can also be modified at later time points by coating of the surfaces.

These approaches will be discussed in more detail in the following chapters. The review is designed as a narrative update to a previous review from 2009 [41]. It focuses mainly on novel strategies that have been tested under in vivo or in situ settings and with proven or potential clinical relevance in dental practice. We to most part excluded studies based on in vitro experiments that were only tested under in vitro settings or with unlikely clinical relevance.

\section{Biocompatibility of novel materials in dentistry}

When designing novel strategies for the management of microbial adherence and colonization in the oral environment, it is important to keep in mind the biocompatibility of these materials. Biocompatibility refers to the question how these materials interact with the host. In general, it is assessed regarding biodegradation of materials, cytotoxicity toward eukaryotic and microbial cells, interaction with natural materials (e.g., teeth, bones) as well as inflammatory potentials, immunotoxicity, or mutagenicity $[156,157]$. Especially in the oral environment, devices should often last for decades with high durability and low level of biodegradation. Therefore, assessment of biocompatibility should ideally also consider long-term effects, which is often difficult to evaluate.

For example, dental casting alloys are generally composed of often more than six different metals. Due to corrosion, these components can be released and interact with the host [158]. Many of these alloys and its metals, particularly heavy metals, show cytotoxicity toward cell lines and yeast [159-161]. Especially biodegradation of amalgam reached a lot of attention due to the biotoxicity of mercury [162]. Also, the remaining unpolymerized fractions from resin-based composite materials or light curing glass ionomer cements (e.g., methacrylates) can lead to cytotoxicity, immunotoxicity, or hypersensitivity [163, 164]. In addition, as outlined before, titanium ions released due to degradation of implants' surfaces may promote microbial dysbiosis as well as inflammatory processes around dental implants $[145,146]$.

Similar problems may arise from the usage of nanoparticles. Functionalization of prosthetic and restorative materials can have beneficial effects on managing microbial colonization but as a downside exhibit unwanted side effects (recently reviewed in [165]). For example nanohydroxyapatite or $\mathrm{TiO}_{2}$ nanoparticles can lead to inflammatory responses and oxidative stress [166].

Nanostructured bactericidal surfaces often pose the problem that they are also detrimental to eukaryotic cells. Surface 
structures can pierce eukaryotic cells, which may lead to cell death or cell stress. Human fibroblast foreskin cells exhibited altered morphologies on 3D nanoposts [167]. However, other studies showed no effects of nanopores on attachment, morphology, and metabolic activity of fibroblasts [168].

\section{Surface roughness and topography}

Traditionally, surface roughness of dental restorative materials was reduced to limit bacterial adhesion and biofilm formation (recently reviewed in [169]). It is commonly believed that higher surface roughness influences bacterial attachment mainly by increasing the surface area (Fig. 6a). Additionally, it was suggested that higher surface roughness leads to higher microbial colonization since it offers shelter against shear forces especially at initial attachment (Fig. 6b) and because they are more difficult to clean compared with smooth surfaces $[44,76,170]$. Indeed, many in situ or in vivo studies showed that reduction of surface roughness reduced bacterial adhesion on commonly used implant materials. For example, reducing surface roughness of titanium or zirconia alloys reduced colonization and biofilm formation [171-174]. However, other in vivo or in situ studies contradict this opinion and suggest that modification of surface roughness only plays a modest role in altering bacterial adherence and biofilm formation [175-179]. Some in vivo and in vitro studies also indicate that surface roughness on dental materials only has a significant impact if the average height $\left(R_{\mathrm{a}}\right)$ is larger than $0.2 \mu \mathrm{m}[44,180-182]$.

In this respect, it is important to remember that all surfaces exposed to the oral cavity are covered by the acquired pellicle within short amounts of time. As outlined before, the pellicle can level out surface roughness [75-78]. This might explain contradictory results between different studies depending on the exactly utilized model as well as between in vitro and in vivo studies [179]. In addition roughness is commonly defined by different parameters like average height $\left(R_{\mathrm{a}}\right)$, root mean square roughness $\left(R_{\mathrm{q}}\right)$, and ten-point height $\left(R_{\mathrm{z}}\right)$ [183]. Depending on the applied parameters and methods for assessing roughness as well as the measured area, similar surfaces can end up having different "roughness values," while surfaces with different topographies may have similar "roughness values" [184-186]. In addition, bacteria can modulate the expression of virulence genes depending on the surface topography. For example, Escherichia coli differentially expresses among others type 1 fimbriae and the Cpx two-component system, a general stress response system, when being grown on nanostructured gold surfaces at least under in vitro conditions $[187,188]$.

\section{Surface charge and energy}

Similarly, charge and surface energy influence adherence of microorganisms. Since the outer layer of bacteria is negatively charged, they tend to adhere better to positively than negatively charged surfaces according to in vitro studies [189, 190] (Fig. 6c). Furthermore, bacteria tend to adhere best to surfaces with moderate wettability compared with highly hydrophobic or hydrophilic surfaces. In vitro studies suggest that in general water contact angles in the range of $40^{\circ}$ to $130^{\circ}$ seem to lead to the highest bacterial adhesion [191-193]. Accordingly, coating of stainless steel or alumina ceramic with hydrophobic hexadecyltrimethoxysilane or perfluorodecyltriethoxysilane reduced biofilm retention in a microcosm model using human saliva [194]. Similarly, coating of titanium or stainless steel surfaces with hydrophobic polytetrafluoroethylene strongly reduced biofilm formation in in situ approaches $[195,196]$. In addition, coating of enamel or titanium with a low surface free energy nanocomposite (NANOMER) could successfully

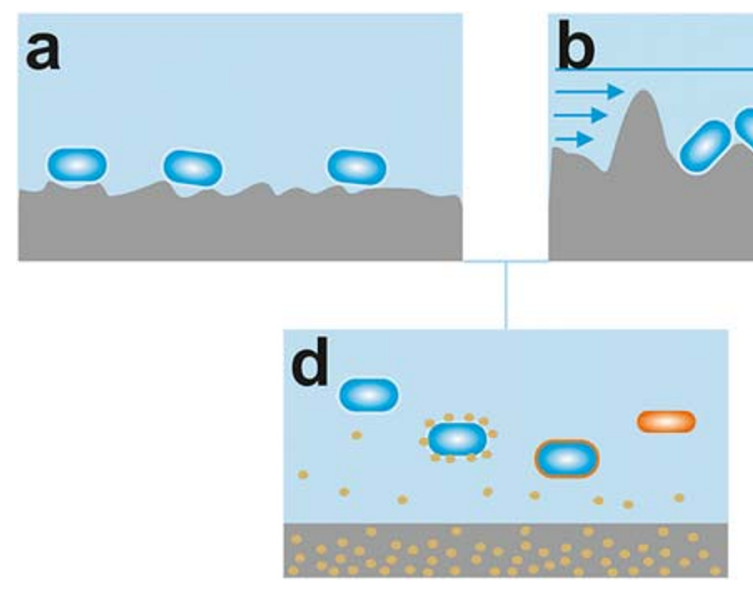

Fig. 6 Interaction of bacteria with different surface properties. Rough surfaces increase the surface area (a) or offer protection against shear forces (b). c Since bacterial membranes are generally negatively charged, positively charged surfaces are generally attractant and negatively charged surfaces repellent. d Functionalized nanoparticles
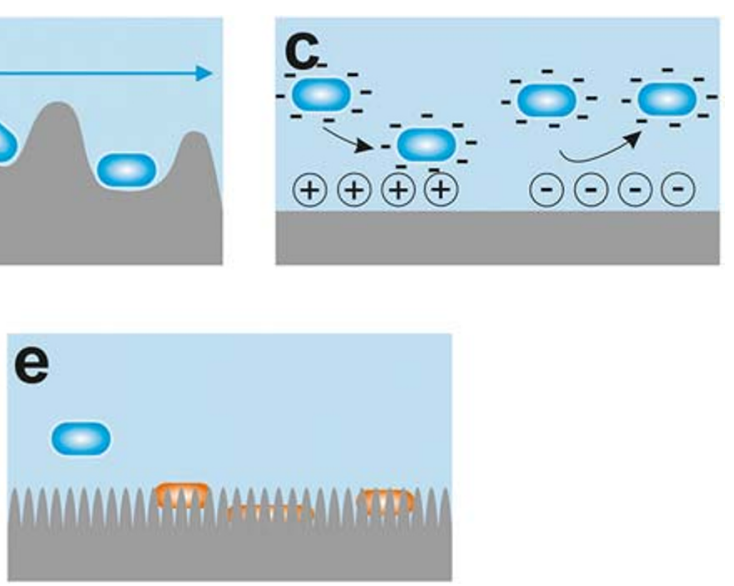

embedded into surfaces with anti-adhesive or antimicrobial properties can prevent attachment or proliferation of bacteria after surface contact or they are released into the surrounding environment. e Nanotextured superhydrophic surfaces are often bactericidal due to stretching of the membrane 
and strongly reduce biofilm formation in situ [155]. Coating with the nanocomposite reduced the thickness as well as the protein-protein adsorption and interaction forces of the acquired oral pellicle. This lead to easier removal of the pellicle and, henceforth, easier detachment of the overlying biofilm thereby promoting "easy-to-clean" properties.

Especially superhydrophobic surfaces tend to reduce bacterial adherence and biofilm formation. These often have microscaled structures on their surface that result in high contact angles. By this means, a superhydrophobic state is reached leading to a self-cleaning effect by rolling off water [197, 198]. This reduces bacterial colonization by simply washing off colonizing bacteria and developing biofilm structures. Furthermore, air becomes entrapped between nanoscale structures. Consequently, the contact area as well as the adhesive forces between bacteria and substrate is reduced. In recent years, many artificial superhydrophobic surfaces on, for example, aluminum, titanium, or polypyrene were developed that successfully reduced bacterial adhesion at least in vitro [199-201]. Although almost no data are available upon the suitability of these approaches for the oral cavity, these approaches justify further research for their applicability due to the nontoxic nature of this approach. However, it should be noted that some studies suggest that the effect of superhydrophobic structures may be short lived. The entrapped air-bubble layer can get lost over time since liquids penetrate the nanostructures (in more detail later). This may then actually promote bacterial adhesion due to increased surface areas [202, 203].

\section{Functionalization of dental materials with antimicrobial activities}

Another strategy to reduce bacterial attachment and biofilm formation on dental implants as well as crowns or fillings is either chemical modification of the materials or the linkage with molecules with antimicrobial activity. A drawback of these approaches might be sustainability since chemical modifications or antimicrobial activities may get lost over time. We will give here an exemplary overview of studies with promising potential.

In several approaches, copper, silver, gold, iron oxide, or zinc oxide nanoparticles were incorporated into resin-based composites like chitosan or other matrices and showed antimicrobial activity at least in vitro [204-209]. They generally act by disruption of the bacterial membrane through physical interaction with the nanoparticles, generation of oxidative stress, and enhanced release of free metal ions (Fig. 6d) (reviewed in [210]). Incorporation of silver-doped bioactive glass into resin-based composites allowed remineralization of dental surfaces and protection against in vitro formed biofilms by $S$. mutans and L. casei [211]. Titan substrates modified with a thin layer of graphene oxide and silver nanoparticles also reduced adhesion with increased bactericidal activity toward S. mutans. Furthermore, expression of the genes encoding for the main subunit of type 1 fimbria FimA and for the glucosyltransferases GtfB and GtfC was significantly reduced [212]. Unfortunately, all these studies were conducted in vitro, while to our knowledge, no in vivo or in situ data are available yet. Also, modifications of PMMA were developed to reduce adherence of Candida spp. like incorporation of nanodiamonds or silver/bromide/cationic polymer nanocomposite (AgBr/NPVP) as well as coating with polyacrylic acid or polycationic acid [213-215].

Quaternary ammonium methylacrylates like dimethylaminododecyl methacrylate incorporated into glass ionomer cement could reduce biofilm formation and microbial viability in situ [216]. It also sustained its properties and showed minimal signs of aging even after incubation in water for at least 6 months, suggesting longterm stability in the oral environment [217]. Incorporation of chlorhexidine salts into glass ionomer cements could also significantly limit microbial counts under in vivo conditions in shorter-term studies up to 7 days, and even after 1 year, still a reduction could be observed [218, 219]. Similarly, resin-based composite materials containing octenidine dihydrochloride $(\mathrm{ODH})$ strongly reduced biofilm formation as well as the fraction of viable microbial cells in situ [220]. Chitosan itself also has antimicrobial activities at acidic $\mathrm{pH}$ [221]. It could reduce biofilm formation in in vitro studies when being incorporated into resin-based composite materials [222]. Some studies also tried to successfully disrupt biofilm formation by impairing adhesion between Streptococci and Porphyromonas [223, 224]. Xu et al. [225] tested a combination of both chemical and topological modifications of surfaces using polyurethane with a pillared topography and a S-nitroso-Nacetylpenicillamine (SNAP) layer releasing NO. Although both treatments alone were able to reduce biofilm formation by Staphylococcus epidermidis, in combination, they showed a synergistic effect.

In summary, chemical modifications of surfaces with antimicrobial properties has promising potential. However, as already mentioned, sustainability of these structures or materials for prolonged time periods in the oral cavity has to be evaluated. Furthermore, biocompatibility of these approaches needs further attention especially in regard to long-term toxicity. In addition, long-term exposure to quaternary ammonium compounds and other antimicrobial substances may lead to the development of resistances in bacteria [226]. This may lead to selection for resistant bacteria in the oral cavity hence counteracting antifouling properties of the surfaces. If resistance genes are encoded on mobile elements, they may also spread to other species in the oral cavity [227]. Nevertheless, promising potential definitely warrants further research in this direction. 


\section{A broader view on antibioadhesion strategies in life sciences}

The former chapter gave an overview about the state of the art of biofilm management in dentistry, and it has been shown that there is still a need for improvements. Therefore, in the following chapter, we will elucidate antibioadhesion strategies in a broader context in order to figure out promising and appropriate tools for future application in the oral cavity. We will concentrate on research and perspectives of physicochemical interfacial properties considering the challenge of biocompatibility.

\section{Surface structure}

Parameters like surface structuring and roughness were investigated for decades and a vast amount of publications exists, which describe their impact on bacterial colonization. Structural parameters were evaluated from the nanoscale (approximate size of molecules and cell appendages) up to the microscale (approximate size of cells or larger) [228, 229], thereby microscaled structures are mostly periodic topographies described by their structural features and nanoscaled structures usually are semiperiodic or random topographies described by roughness parameters [230, 231]. Structures much larger than cells do not directly have relevance for prevention of biofouling processes as they provide niches that can support undisturbed attachment and resistance against removal. But large structures can have a secondary advantage if they are part of a hierarchical structure in which they provide mechanical support against abrasion of smaller structural levels [232-234]. However, on simple surface structures, strong interactions between bacteria and substrate as well as clear adhesion patterns in the initial colonization phase could be observed if the structural dimensions (size and spacing) were in the cell size range [228, 230, 231, 235-240]. In contrast, for structure sizes slightly below the bacterial cell size (submicron scale), inhibition of the initial microbial adhesion could be observed [229, 241, 242]. For much smaller nanostructures, the reported effects differ strongly between being high and low adhesive [243, 244]. It has been shown that even the smallest differences in surface nanoroughness can strongly affect microbial cells' attachment [245-250]. These variations must be connected with certain spacings of bacterial adhesion sites on the membrane or cell appendages, but there is no direct evidence in the literature so far. Additionally, nanostructured surfaces can alter protein adsorption in comparison to the flat material, because small curvature radii of structural features can influence protein conformation and disturb molecular alignment (Fig. 1c) [251]. Thus, depending on the native protein shape (such as globular for BSA vs. elongated for fibrinogen), small surface structures can either decrease or increase adsorption [252]. However, there are many contradictory experimental observations on the effect of micro- and nanostructured surfaces on biomolecular adsorption and bacterial colonization $[228,235,236,238-240,253$, 254]. These contradictions arise often due to inconsistent comparison of physicochemical properties of the samples and the use of differing biomolecules/bacterial strains as well as general differences between experimental setups/parameters. This illustrates clearly that systematic research on the effect of different scales on surface structures on bacterial colonization in an easily accessible clinically relevant environment (oral cavity) is strongly required.

\section{Surface free energy and elasticity}

Controlling the surface chemistry (i.e., surface free energy and/or elasticity) of a substrate is another promising approach to control biofouling. Substrates with low and high surface free energies in particular have been shown to affect biomolecule adsorption and bacterial adhesion [255]. Hydrophilic surfaces featuring high surface free energies, such as poly(ethylene glycol) (PEG)-based coatings, can inhibit biofouling by steric repulsion due to chain compression and the "barrier" created by structured water associated with the PEG chains [256]. An opposite approach is the use of hydrophobic coatings with low surface free energies, sometimes called theta surfaces [257]. These surfaces do not inhibit adsorption/ adhesion per se, but allow for an easy removal of adsorbates and biofilms [257]. Furthermore, the use of soft surfaces could reduce attachment of certain bacterial strains [258, 259]. However, there are also bacterial strains which adhere well to soft substrates, especially if specific adhesion sites for protein-protein or protein-saccharide interactions exist, i.e., on eukaryotic tissue, mucosa, or adsorbed protein layers on artificial substrates [260-263]. Nevertheless, there are bacterial strains which do not show significant changes of adhesion over different magnitudes of material stiffness [264].

\section{Bio-inspired strategies}

In recent years, research on improved biomedical surfaces started to focus on mimicking natural (e.g., shark skin, lotus and taro leaves, cicadia wings, springtail's cuticle, or pitcher plants) antifouling (reduced microbial adherence or attachment) or bactericidal (active killing of bacteria) surfaces (recently reviewed in [265]). The antifouling properties of these surfaces are generally explained by their hydrophobic nature combined with a nanopillared geometry leading to a superhydrophobic ("nonwetted") state as explained by the Wenzel and Cassie-Baxter model and the so-called lotus effect [266-268]. In this state, only a very small contact exists between the contaminated liquid and the substrate, which reduces the spatial opportunity for bioadhesion, and liquids roll off immediately at the slightest tilt, which reduces the 
temporal opportunity for fouling processes. Repellency against aqueous media can be observed on many plants but also on arthropod cuticles. Springtails were found to be even more repellent as they can resist wetting against liquids with low surface tensions (oil, ethanol, etc.) [269, 270] by submicroscaled structures with overhanging cross-sectional profiles [271]. Another strategy for preventing bacterial colonization is the utilization of "slippery" covering layers on harder substrates found on pitcher plants [272, 273]. The slippery substrate strongly prevents bacterial adhesion, because there is almost no appropriate counterpart for adhesion in the slime.

Depending on the size and distribution of nanotopographies, surface structures can also act bactericidal than just prevent adhesion. The mechanism of cicadia wings and similar structures is explained by their small feature size $(\sim 50-100 \mathrm{~nm})$ and the high aspect ratio [274-276]. This leads to stretching and puncture of the bacterial membrane and subsequent cell lysis either by suspension of the membrane between pillars (biophysical model) or by "tearing" of the membrane due to an increase in the surface contact area (thermodynamic model) [154, 277, 278] (Fig. 6e). While most of these structures were never applied to the oral cavity, exposure of springtail cuticles to saliva was tested in situ and a modulated process of initial bioadhesion was observed. In contrast to a pellicle homogenously coating all surface structures, there was at least in part the formation of proteinaceous membranelike structures bridging the springtail's cuticle nanostructures. As a result, springtails could modulate bacterial adhesion on short-term time points but lost its specific properties after exposure for a few hours [241]. This clearly indicates the relevance of early in situ experiments.

To transfer innovative biomimetic strategies to medical and dental surface devices, silicon- or titania-based nanostructured surfaces are increasingly evaluated for their suitability. For example, nanostructures were generated on silicon surfaces by ion etching via a silicon wafer ([279] or fabrication of nanocone-shaped diamonds on silicon substrates [280]. In vitro, these structures were able to kill E. coli, Staphylococcus aureus, or Pseudomonas aeruginosa. Titanium surfaces containing nanowires with a diameter of ca. $100 \mathrm{~nm}$ were efficient in killing motile bacteria like P. aeruginosa, E. coli, or Bacillus subtilis [275]. In similar approaches, nanoscale structures were introduced onto different materials like alumina surfaces thereby limiting bacterial attachment [281-283]. Nanopores of 20-25 nm were introduced onto stainless steel by electrochemical etching [168]. This modification leads to substantially reduced adhesion of $S$. aureus and E. coli while not affecting attachment, morphology, and metabolic activity of fibroblasts, suggesting good biocompatibility of these materials.

Unfortunately, most of these data were obtained under in vitro laboratory conditions, while these structures were rarely evaluated for their suitability in the oral cavity. However, micropatterning of titanium surfaces by laser etching leads to reduced biofilm formation in situ compared with machined or grit-blasted surfaces [284]. Also, few studies were conducted in the oral environment. However, Miao et al. showed reduced initial adhesion of the oral pathogen S. mutans to nanotextured compared with smooth or microtextured titanium surfaces while at the same time improving attachment of human gingival epithelial cells or fibroblasts [285]. Also, a nanotextured titanium surface with an average roughness of approximately $10 \mathrm{~nm}$ could reduce surface colonization of $A$. actinomycetemcomitans compared with untreated titanium surfaces [286].

Hence, promising in vitro results and a likely good biocompatibility of these materials definitely warrant further in vivo or in situ studies to elucidate their applicability in the oral cavity. Nanostructured implant materials mimicking natural antifouling materials definitely have the potential to efficiently modulate and reduce biofilm formation on oral medical devices and materials.

\section{Heterogeneous surface properties}

Recently, materials, which combine different or even opposite physicochemical properties within a molecule, along a polymer chain or across a surface area came into the focus of intense research. Low bioadhesion could be shown for coatings with zwitterionic polymers like phosphorylcholin or polybetains [287-291]. The close proximity of negative and positive charges leads to a strong hydration which reduces protein adsorption. Furthermore, amphiphilic surfaces with nanometer-sized hydrophilic and hydrophobic domains were among others achieved by nanocomposites, block copolymers, hyperbranched fluorpolymer-PEG, and fluorpolymerPDMS-PEG networks, whereas micrometer-sized domains were realized using a Janus-particle-based system [255, 292, 293]. Low cell adhesion and good fouling release properties of these bi- or multiphasic interfaces were reported to often outperform surfaces featuring just monophasic properties. For some of the tested surfaces, also reduced protein adsorption was reported. On chemically nanoscaled heterogeneous silica-zirconia surfaces, the net amount of adsorbed albumin was higher than predicted by the average of adsorption on both monophases [294]. Other research groups have reported an opposite effect on biphasic microscaled substrates [295, 296], but no convincing explanation of the altered adsorption had been presented. Polyelectrolyte multilayer coatings were found to reduce protein adsorption, whereby it was hypothesized that the formed nanoscaled domains and the low surface net charge are the origin of this effect [297]. However, it is plausible that spatial alterations of different chemical phases in the range of the protein sizes influence adsorption processes 
and conformational changes, analogous to surface structures with curvature radii in the nanoscale [297-300].

\section{Discussion}

In recent years, a plethora of studies tested multitudes of approaches to construct novel low-fouling or antibactericidal surfaces to reduce attachment of microorganisms or biofilm formation on biomedical surfaces in dentistry and beyond. In an ideal situation, prosthetic dental materials should closely mimic natural dental structures without their downsides. They should be resistant to erosion by substances produced by the host and microbiota in the oral environment. In addition, most prosthetic materials in the oral cavity should function for years or even decades. Hence, low-fouling or antibactericidal activities must last for extended periods of time without deterioration or loss in functionality. This should be kept in mind especially for approaches employing chemical modifications or nanocarriers. While they may well work on short-term perspectives, their long-term viability is often questionable. Another important aspect is biocompatibility of restorative materials in the oral environment. It is important that they do not cause toxic reactions to the host both on a short- and longterm time span. Especially approaches employing chemical modifications, nanoparticles, or nanocarriers may present problems with biocompatibility. While some studies examined biocompatibility, many studies lack data in that direction. Importantly, novel materials must be moldable to be implemented into the existing dental environment without cracks and crevices. Other aspects to be considered are costeffectiveness and acceptance by patients.

In the oral cavity, surfaces are almost instantly covered by the acquired pellicle [61, 147]. As outlined before, the

Fig. 7 Interaction of bacteria and proteins with biphasic interfaces. a Bacteria can adhere to surfaces with various interfacial properties but might have problems to adapt to surfaces with alternating interfacial properties. b Protein adsorption transforms the synthetic textured identity into a biological alternating identity. $\mathbf{c}$ Nanotextures allow bioadhesion but might lead to easy removal
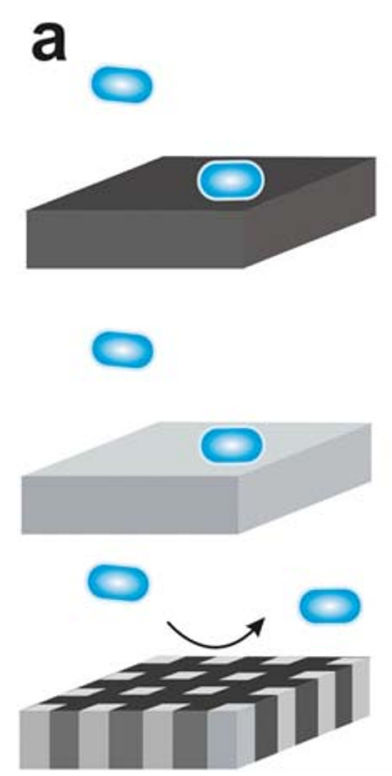

presence of the pellicle may mask or alter structural properties of surfaces like roughness, wettability, and hydrophilicity or hydrophobicity [74-76, 78, 80]. Furthermore, the pellicle itself presents attachment points for the adhesion of microorganisms as well as possessing antimicrobial properties [61, 69]. Hence, surface modifications that work well in reducing biofilm formation in implants outside of the oral cavity (e.g., joint replacements) may not be efficient in the oral cavity due to the presence of the acquired oral pellicle. On the other hand, these phenomena make the oral cavity a perfect model to evaluate new strategies in an easily accessible and clinically relevant model.

In addition, studies employing similar approaches have often inconclusive or even contradictory results. Similar approaches may have a protective effect in some studies, while other studies showed no effect or even lead to enhanced microbial adhesion or biofilm formation (e.g., surface roughness) [171-179]. Reasons may often be the design of the study (e.g., in vitro vs. in situ or in vivo; models used for the study; or time frames). Structural alterations of surface properties also often affect several physical and chemical properties like roughness, surface wettability, hydrophobicity, or hydrophilicity [301]. This makes it often challenging to pinpoint specific effects on adhesion or biofilm formation to one specific property. Finally, different biophysical and biochemical properties (e.g., surface charge, Gram-positive or negative, arsenal of adhesins) of different microorganisms can lead to a change in biofilm community on different restorative materials [69, 189]. It is therefore important to consider that not only the degree of biofilm formation must be considered but also the composition of the community (pathogenic vs. commensal microorganisms).

Traditionally, many studies focused on altering surface properties of structures like surface roughness or surface

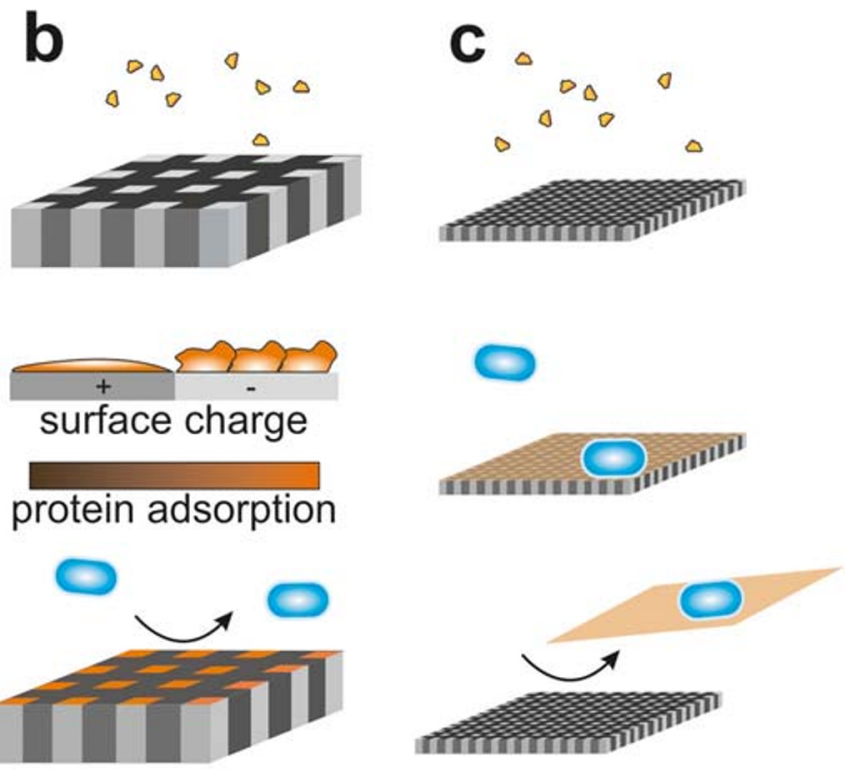


charge or energy with varying success [155, 171, 173-175, 177-179, 194, 196]. In addition, incorporation of antimicrobially active metal ions is a common strategy to limit microbial settlement especially on resin-based composite materials [211, 212]. Nevertheless, many novel promising approaches appeared within the last years. Especially superhydrophobic nanotextured surfaces with both antifouling and/or antimicrobial activity inspired by nature appear promising [241, 284, 286]. In addition, many studies focused on incorporating nanoparticles with antimicrobial or antiadhesive properties mainly into resin-based composite materials [216-220, 302]. The majority of these studies were conducted in vitro showing the general applicability of these approaches. However, more studies directly in the oral environment are necessary to prove "real-life" applicability in the mouth. In addition, long-term stability and biocompatibility were rarely evaluated. Still, these approaches are promising pathways for biofilm management on oral implants or resinbased composite materials and warrant further attention.

The majority of strategies for biofilm management focused on single strategies like easy-to-clean surfaces, bacteriostatic or bactericidal surface properties, or incorporation of antimicrobial substances via surface coupling or nanoparticles or carriers. While some approaches already combined different strategies [225], further improvement may well be achieved by increased combinatory approaches.

Overall, the main question arises which approaches warrant further research in respect to functionality, sustainability, and biocompatibility. While functionalization of surfaces with antimicrobial or anti-adhesive properties might be beneficial in a short-term perspective, sustainability and biocompatibility remain questionable. Modifying roughness or surface charges (wettability) also offered inconclusive results in a plethora of studies. While generation of nanostructured topographies to generate superhydrophobic and/or bactericidal surfaces showed promising results, the question about the long-term prospective of these approaches still remains. First, with few exceptions, these strategies were rarely evaluated in the oral cavity and beneficial protective properties may be lost due to pellicle formation. Secondly, structures limited to the outer surface may not be sustainable in the oral cavity since they will be lost over time due to erosion and degradation of the outermost surface. Although still relatively limited data are available yet, smooth biphasic nano- and microtextures may be very promising in the future. Especially resin-based composites or solid materials with incorporated nano- or microsized insertions combine several favorable features. Used alternations might be polar-nonpolar, positivelynegatively charged, or hard-soft physicochemical properties. Many bacteria can adopt and adhere to interfaces with very different properties, but it is not clarified how well they can adapt to substrates that change their properties across a presumable adhesion area (Fig. 7a). Total vanishing of the synthetic identity of the alternating surface properties by adsorption of biomolecules is most likely a priori prevented, because of translation into a biologically alternating identity due to modulated adsorption intensities (Fig. 7b), alternating molecular conformations, or differently extended hard and soft protein coronas on, for example, surface partitions with low and high energies. Not at least, nanotextures might induce adsorption of loosely bound protein layer, which will delaminate or can easily be removed when reaching a certain thickness or a destabilizing load with microbes (Fig. 7c). Such surfaces would combine anti-adhesive properties with presumable good biocompatibility, and when applied with insertions, antirepellent properties are not limited to the surface, thereby tolerating certain degrees of biodegradation.

\section{Conclusions}

Advances in the design and quality of artificial prosthetic materials in the oral environment and other parts of the body vastly increased the life span and life quality of people. But as outlined, still many problems arise with the control of microbial settlement and propagation on these surfaces. Therefore, it is a worthwhile and challenging endeavor to invest in the improvement of these materials to reduce complications and recurrence of oral and other diseases. In particular, there are many possibilities to improve existing prosthetic or filling materials by nanostructuring or functionalization of surfaces. In addition, combinatorial approaches of several strategies may lead to vastly improved materials for use in the oral environment. However, most promising for the future may be functionalized biphasic structures by incorporation of nanoparticles into existing dental materials due to presumably high functionality, durability, and biocompatibility.

In summary, novel enhanced materials and resin-based composites for coating of dental restorations, fillings, fixed particles, dentures, and prosthetic implants or orthodontic devices will hopefully lead to less complications or failures of these materials, thereby reducing the risk of caries, periodontitis, gingivitis, peri-implantitis, or other implant-related diseases.

Acknowledgments This manuscript was devised in the context of a research project on antifouling surfaces with alternating interfacial properties funded by the DFG research grant HE 7149/3-1.

Authors' contribution $\mathrm{CH}, \mathrm{MH}$, and $\mathrm{RH}$ developed the original idea for the article. TS and RH did the literature research and draft of the manuscript and figures with input from all authors. TS mainly wrote the manuscript with input from all authors. $\mathrm{CH}$ and $\mathrm{MH}$ critically revised the manuscript.

Funding Open Access funding enabled and organized by Projekt DEAL. This work was supported by the DFG research grant HE 7149/3-1. 


\section{Compliance with ethical standards}

Conflict of interest The authors declare that they have no conflict of interest.

Ethical approval This article does not contain any studies with human participants or animals performed by any of the authors.

Informed consent For this type of study, formal consent is not required.

Open Access This article is licensed under a Creative Commons Attribution 4.0 International License, which permits use, sharing, adaptation, distribution and reproduction in any medium or format, as long as you give appropriate credit to the original author(s) and the source, provide a link to the Creative Commons licence, and indicate if changes were made. The images or other third party material in this article are included in the article's Creative Commons licence, unless indicated otherwise in a credit line to the material. If material is not included in the article's Creative Commons licence and your intended use is not permitted by statutory regulation or exceeds the permitted use, you will need to obtain permission directly from the copyright holder. To view a copy of this licence, visit http://creativecommons.org/licenses/by/4.0/.

\section{References}

1. Lamont RJ, Koo H, Hajishengallis G (2018) The oral microbiota: dynamic communities and host interactions. Nat Rev Microbiol 16:745-759. https://doi.org/10.1038/s41579-018-0089-x

2. Dewhirst FE, Chen T, Izard J et al (2010) The human oral microbiome. J Bacteriol 192:5002-5017. https://doi.org/10. 1128/JB.00542-10

3. Rupf S, Laczny CC, Galata V et al (2018) Comparison of initial oral microbiomes of young adults with and without cavitated dentin caries lesions using an in situ biofilm model. Sci Rep 8:14010. https://doi.org/10.1038/s41598-018-32361-x

4. Bowen WH, Burne RA, Wu H, Koo H (2019) Oral biofilms: pathogens, matrix and polymicrobial interactions in microenvironments. Trends Microbiol 26:229-242. https://doi.org/10. 1016/j.tim.2017.09.008.Oral

5. Mark Welch JL, Dewhirst FE, Borisy GG (2019) Biogeography of the oral microbiome: the site-specialist hypothesis. Annu Rev Microbiol 73:335-358. https://doi.org/10.1146/annurev-micro090817-062503

6. He X, McLean JS, Guo L et al (2014) The social structure of microbial community involved in colonization resistance. ISME J 8:564-574. https://doi.org/10.1038/ismej.2013.172

7. Sorbara MT, Pamer EG (2019) Interbacterial mechanisms of colonization resistance and the strategies pathogens use to overcome them. Mucosal Immunol 12:1-9. https://doi.org/10.1038/s41385018-0053-0

8. Graves DT, Corrêa JD, Silva TA (2019) The oral microbiota is modified by systemic diseases. J Dent Res 98:148-156. https:// doi.org/10.1177/0022034518805739

9. Idris A, Hasnain SZ, Huat LZ, Koh D (2017) Human diseases, immunity and the oral microbiota-insights gained from metagenomic studies. Oral Sci Int 14:27-32. https://doi.org/10. 1016/S1348-8643(16)30024-6

10. Pitts NB, Zero DT, Marsh PD et al (2017) Dental caries. Nat Rev Dis Primers 3:17030

11. Dahlen G, Basic A, Bylund J (2019) Importance of virulence factors for the persistence of oral bacteria in the inflamed gingival crevice and in the pathogenesis of periodontal disease. J Clin Med 8:1339. https://doi.org/10.3390/jcm8091339

12. Kurgan S, Kantarci A (2018) Molecular basis for immunohistochemical and inflammatory changes during progression of gingivitis to periodontitis. Periodontol 2000 76:51-67. https://doi.org/ 10.1111/prd.12146

13. Popova C, Dosseva-Panova V, Panov V (2013) Microbiology of periodontal diseases. A review. Biotechnol Biotechnol Equip 27: 3754-3759. https://doi.org/10.5504/BBEQ.2013.0027

14. Nowicki EM, Shroff R, Singleton JA et al (2018) Microbiota and metatranscriptome changes accompanying the onset of gingivitis. MBio 9:e00575-e00518. https://doi.org/10.1128/mbio.00575-18

15. Shi M, Wei Y, Hu W et al (2018) The subgingival microbiome of periodontal pockets with different probing depths in chronic and aggressive periodontitis: a pilot study. Front Cell Infect Microbiol 8:124. https://doi.org/10.3389/fcimb.2018.00124

16. Hajishengallis G, Lamont RJ (2014) Breaking bad: manipulation of the host response by Porphyromonas gingivalis. Eur J Immunol 44:328-338. https://doi.org/10.1002/eji.201344202

17. Hajishengallis G, Lamont RJ (2012) Beyond the red complex and into more complexity: the polymicrobial synergy and dysbiosis (PSD) model of periodontal disease etiology. Mol Oral Microbiol 27:409-419. https://doi.org/10.2217/FON.09.6. Dendritic

18. Deng ZL, Szafrański SP, Jarek M et al (2017) Dysbiosis in chronic periodontitis: key microbial players and interactions with the human host. Sci Rep 7:3703. https://doi.org/10.1038/s41598-01703804-8

19. Topcuoglu N, Kulekci G (2015) 16S rRNA based microarray analysis of ten periodontal bacteria in patients with different forms of periodontitis. Anaerobe 35:35-40. https://doi.org/10.1016/j. anaerobe.2015.01.011

20. Smeets R, Henningsen A, Jung O et al (2014) Definition, etiology, prevention and treatment of peri-implantitis - a review. Head Face Med 10:34. https://doi.org/10.1186/1746-160X-10-34

21. Askar H, Krois J, Göstemeyer G et al (2020) Secondary caries: what is it, and how it can be controlled, detected, and managed? Clin Oral Investig 24:1869-1876. https://doi.org/10.1007/s00784020-03268-7

22. Kim J (2018) Mathematical modeling approaches to describe the dynamics of protein adsorption at solid interfaces. Colloids Surfaces B Biointerfaces 162:370-379. https://doi.org/10.1016/j. colsurfb.2017.12.006

23. Langmuir I (1918) The adsorption of gases on plane surfaces of glass, mica and platinum. J Am Chem Soc 40:1361-1403. https:// doi.org/10.1021/ja02242a004

24. Schaaf P, Talbot J (1989) Surface exclusion effects in adsorption processes. J Chem Phys 91:4401-4409. https://doi.org/10.1063/1. 456768

25. Faccio G (2018) From protein features to sensing surfaces. Sensors (Switzerland) 18:1204. https://doi.org/10.3390/ s18041204

26. Marsh JA, Teichmann SA (2011) Relative solvent accessible surface area predicts protein conformational changes upon binding. Structure 19:859-867. https://doi.org/10.1016/j.str.2011.03.010

27. Roach P, Farrar D, Perry CC (2005) Interpretation of protein adsorption: surface-induced conformational changes. J Am Chem Soc 127:8168-8173. https://doi.org/10.1021/ja042898o

28. Magyari K, Vanea E, Baia L, Simon V (2016) Attachment and conformational changes of collagen on bioactive glass surface. Biomed Mater Eng 27:63-74. https://doi.org/10.3233/BME161567

29. Sanfeld A, Royer C, Steinchen A (2015) Thermodynamic, kinetic and conformational analysis of proteins diffusion-sorption on a solid surface. Adv Colloid Interface Sci 222:639-660. https://doi. org/10.1016/j.cis.2014.10.006 
30. Hirsh SL, McKenzie DR, Nosworthy NJ et al (2013) The Vroman effect: competitive protein exchange with dynamic multilayer protein aggregates. Colloids Surfaces B Biointerfaces 103:395-404. https://doi.org/10.1016/j.colsurfb.2012.10.039

31. Horbett TA (2018) Fibrinogen adsorption to biomaterials. J Biomed Mater Res A 106:2777-2788. https://doi.org/10.1002/ jbm.a.36460

32. Keskin O, Tuncbag N, Gursoy A (2016) Predicting proteinprotein interactions from the molecular to the proteome level. Chem Rev 116:4884-4909. https://doi.org/10.1021/acs.chemrev. 5 b00683

33. Zhou HX, Pang X (2018) Electrostatic interactions in protein structure, folding, binding, and condensation. Chem Rev 118: 1691-1741. https://doi.org/10.1021/acs.chemrev.7b00305

34. Mulheran PA, Connell DJ, Kubiak-Ossowska K (2016) Steering protein adsorption at charged surfaces: electric fields and ionic screening. RSC Adv 6:73709-73716. https://doi.org/10.1039/ c6ra16391b

35. Rabe M, Verdes D, Seeger S (2011) Understanding protein adsorption phenomena at solid surfaces. Adv Colloid Interface Sci 162:87-106. https://doi.org/10.1016/j.cis.2010.12.007

36. Falde EJ, Yohe ST, Colson YL, Grinstaff MW (2016) Superhydrophobic materials for biomedical applications. Biomaterials 104:87-103. https://doi.org/10.1016/j.joca.2009. 09.009

37. Migliorini E, Weidenhaupt M, Picart C (2018) Practical guide to characterize biomolecule adsorption on solid surfaces (review). Biointerphases 13:06D303. https://doi.org/10.1116/1.5045122

38. Guo J, Yao X, Ning L et al (2014) The adsorption mechanism and induced conformational changes of three typical proteins with different secondary structural features on graphene. RSC Adv 4: 9953-9962. https://doi.org/10.1039/c3ra45876h

39. Carniello V, Peterson BW, van der Mei HC, Busscher HJ (2018) Physico-chemistry from initial bacterial adhesion to surfaceprogrammed biofilm growth. Adv Colloid Interface Sci 261:114. https://doi.org/10.1016/j.cis.2018.10.005

40. Hannig M, Joiner A (2006) The structure, function and properties of the acquired pellicle. Teeth Their Environ 19:29-64. https://doi. org/10.1159/000090585

41. Hannig C, Hannig M (2009) The oral cavity - a key system to understand substratum-dependent bioadhesion on solid surfaces in man. Clin Oral Investig 13:123-139. https://doi.org/10.1007/ s00784-008-0243-3

42. Hermansson M (1999) The DLVO theory in microbial adhesion. Colloids Surfaces B Biointerfaces 14:105-119

43. Van Der Westen R, Sjollema J, Molenaar R et al (2018) Floating and tether-coupled adhesion of bacteria to hydrophobic and hydrophilic surfaces. Langmuir 34:4937-4944. https://doi.org/10. 1021/acs.langmuir.7b04331

44. Teughels W, Van Assche N, Sliepen I, Quirynen M (2006) Effect of material characteristics and/or surface topography on biofilm development. Clin Oral Implants Res 17:68-81. https://doi.org/ 10.1111/j.1600-0501.2006.01353.x

45. Hori K, Matsumoto S (2010) Bacterial adhesion: from mechanism to control. Biochem Eng J 48:424-434. https://doi.org/10.1016/j. bej.2009.11.014

46. Spengler C, Thewes N, Jung P et al (2017) Determination of the nano-scaled contact area of staphylococcal cells. Nanoscale 9: 10084-10093. https://doi.org/10.1039/c7nr02297b

47. Thewes N, Loskill P, Jung P et al (2014) Hydrophobic interaction governs unspecific adhesion of staphylococci: a single cell force spectroscopy study. Beilstein J Nanotechnol 5:1501-1512. https:// doi.org/10.3762/bjnano.5.163

48. Sjollema J, Van Der Mei HC, Hall CL et al (2017) Detachment and successive re-attachment of multiple, reversibly-binding tethers result in irreversible bacterial adhesion to surfaces. Sci Rep 7:4369. https://doi.org/10.1038/s41598-017-04703-8

49. Chen Y, Harapanahalli AK, Busscher HJ et al (2014) Nanoscale cell wall deformation impacts long-range bacterial adhesion forces on surfaces. Appl Environ Microbiol 80:637-643. https://doi.org/ 10.1128/AEM.02745-13

50. Harapanahalli AK, Chen Y, Li J et al (2015) Influence of adhesion force on icaA and cidA gene expression and production of matrix components in Staphylococcus aureus biofilms. Appl Environ Microbiol 81:3369-3378. https://doi.org/10.1128/AEM.04178-14

51. Wang C, Hou J, van der Mei HC et al (2019) Emergent properties in Streptococcus mutans biofilms are controlled through adhesion force sensing by initial colonizers. MBio 10:e1908-e19018. https://doi.org/10.1128/mbio.01908-19

52. Ren Y, Wang C, Chen Z et al (2018) Emergent heterogeneous microenvironments in biofilms: substratum surface heterogeneity and bacterial adhesion force-sensing. FEMS Microbiol Rev 42: 259-272. https://doi.org/10.1093/femsre/fuy001

53. Kim J, Kim HS, Han S et al (2013) Hydrodynamic effects on bacterial biofilm development in a microfluidic environment. Lab Chip 13:1846-1849. https://doi.org/10.1039/c3lc40802g

54. Thomen P, Robert J, Monmeyran A et al (2017) Bacterial biofilm under flow: first a physical struggle to stay, then a matter of breathing. PLoS One 12:e175197. https://doi.org/10.1371/journal. pone. 0175197

55. Wenzel RN (1936) Resistance of solid surfaces to wetting by water. Ind Eng Chem 28:988-994

56. Simpson JT, Hunter SR, Aytug T (2015) Superhydrophobic materials and coatings: a review. Reports Prog Phys 78:86501. https://doi.org/10.1088/0034-4885/78/8/086501

57. Yang C, Tartaglino U, Persson BNJ (2008) Nanodroplets on rough hydrophilic and hydrophobic surfaces. Eur Phys J E 25: 139-152. https://doi.org/10.1140/epje/i2007-10271-7

58. Cassie ABD, Baxter S (1944) Wettability of porous surfaces. Trans Faraday Soc 40:546-551

59. Zhang X, Wang L, Levänen E (2013) Superhydrophobic surfaces for the reduction of bacterial adhesion. RSC Adv 3:12003-12020. https://doi.org/10.1039/c3ra40497h

60. Hannig M, Hannig C (2014) The pellicle and erosion. In: Lussi A, Ganss C (eds) Erosive tooth wear: from diagnosis to therapy, vol 25. Karger, Basel, pp 206-214. https://doi.org/10.1159/ 000360376

61. Siqueira WL, Custodio W, McDonald EE (2012) New insights into the composition and functions of the acquired enamel pellicle. J Dent Res 91:1110-1118. https://doi.org/10.1177/ 0022034512462578

62. Hannig M (1999) Ultrastructural investigation of pellicle morphogenesis at two different intraoral sites during a 24 -h period. Clin Oral Investig 3:88-95

63. Güth-Thiel S, Kraus-Kuleszka I, Mantz H et al (2019) Comprehensive measurements of salivary pellicle thickness formed at different intraoral sites on Si wafers and bovine enamel. Colloids Surfaces B Biointerfaces 174:246-251. https://doi.org/ 10.1016/j.colsurfb.2018.11.020

64. Schweigel H, Wicht M, Schwendicke F (2016) Salivary and pellicle proteome: a datamining analysis. Sci Rep 6:38882. https:// doi.org/10.1038/srep38882

65. Hannig M (1997) Transmission electron microscopic study of in vivo pellicle formation on dental restorative materials. Eur J Oral Sci 105:422-433

66. Cassiano LPS, Ventura TMS, Silva CMS et al (2018) Protein profile of the acquired enamel pellicle after rinsing with whole milk, fat-free milk, and water: an in vivo study. Caries Res 52: 288-296. https://doi.org/10.1159/000485390

67. Trautmann S, Barghash A, Fecher-Trost C et al (2019) Proteomic analysis of the initial oral pellicle in caries-active and caries-free 
individuals. Proteomics Clin Appl 13:1800143. https://doi.org/10. 1002/prca.201800143

68. Delius J, Trautmann S, Médard G et al (2017) Label-free quantitative proteome analysis of the surface-bound salivary pellicle. Colloids Surfaces B Biointerfaces 152:68-76. https://doi.org/10. 1016/j.colsurfb.2017.01.005

69. Nobbs AH, Jenkinson HF, Jakubovics NS (2011) Stick to your gums: mechanisms of oral microbial adherence. J Dent Res 90: 1271-1278. https://doi.org/10.1177/0022034511399096

70. Cisar JO, Takahashi Y, Ruhl S et al (1997) Specific inhibitors of bacterial adhesion: observations from the study of gram-positive bacteria that initiate biofilm formation on the tooth surface. Adv Dent Res 11:168-175

71. Ruhl S, Sandberg AL, Cisar JO (2004) Salivary receptors for the proline-rich protein-binding and lectin-like adhesins of oral actinomyces and streptococci. J Dent Res 83:505-510. https://doi.org/ $10.1177 / 154405910408300614$

72. Kirsch J, Hannig C, Pötschke S et al (2017) Enzymology and ultrastructure of the in situ pellicle in caries-active and cariesinactive patients. Caries Res 51:109-118. https://doi.org/10. $1159 / 000452226$

73. Schulz A, Lang R, Behr J et al (2020) Targeted metabolomics of pellicle and saliva in children with different caries activity. Sci Rep 10:697. https://doi.org/10.1038/s41598-020-57531-8

74. Milosevic A (1992) The influence of surface finish and in-vitro pellicle on contact-angle measurement and surface morphology of three commercially available composite restoratives. J Oral Rehabil 19:85-97. https://doi.org/10.1111/j.1365-2842.1992. tb01593.x

75. McConnell MD, Liu Y, Nowak AP et al (2010) Bacterial plaque retention on oral hard materials: effect of surface roughness, surface composition, and physisorbed polycarboxylate. J Biomed Mater Res A 92:1518-1527. https://doi.org/10.1002/jbm.a.32493

76. Park JW, Song CW, Jung JH et al (2012) The effects of surface roughness of composite resin on biofilm formation of Streptococcus mutans in the presence of saliva. Oper Dent 37: 532-539. https://doi.org/10.2341/11-371-L

77. Cavalcanti YW, Soare RV, Leite Assis MA et al (2015) Titanium surface roughing treatments contribute to higher interaction with salivary proteins MG2 and lactoferrin. J Contemp Dent Pract 16: 141-146. https://doi.org/10.5005/jp-journals-10024-1651

78. Ionescu AC, Cazzaniga G, Ottobelli M et al (2018) In vitro biofilm formation on resin-based composites cured under different surface conditions. J Dent 77:78-86. https://doi.org/10.1016/j.jdent.2018. 07.012

79. Cheaib Z, Rakmathulina E, Lussi A, Eick S (2015) Impact of acquired pellicle modification on adhesion of early colonizers. Caries Res 49:626-632. https://doi.org/10.1159/000442169

80. Cavalcanti YW, Wilson M, Lewis M et al (2016) Salivary pellicles equalise surfaces' charges and modulate the virulence of Candida albicans biofilm. Arch Oral Biol 66:129-140. https://doi.org/10. 1016/j.archoralbio.2016.02.016

81. Kline KA, Fälker S, Dahlberg S et al (2009) Bacterial adhesins in host-microbe interactions. Cell Host Microbe 5:580-592. https:// doi.org/10.1016/j.chom.2009.05.011

82. Vengadesan K, Narayana SVL (2011) Structural biology of Gram-positive bacterial adhesins. Protein Sci 20:759-772. https://doi.org/10.1002/pro.613

83. Hansmeier N, Miskiewicz K, Elpers L et al (2017) Functional expression of the entire adhesiome of Salmonella enterica serotype Typhimurium. Sci Rep 7:1-12. https://doi.org/10.1038/s41598017-10598-2

84. Sullan RMA, Li JK, Crowley PJ et al (2015) Binding forces of Streptococcus mutans P1 adhesin. ACS Nano 9:1448-1460. https://doi.org/10.1021/nn5058886
85. Liang X, Liu B, Zhu F et al (2016) A distinct sortase SrtB anchors and processes a streptococcal adhesin AbpA with a novel structural property. Sci Rep 6:30966. https://doi.org/10.1038/ srep30966

86. Back CR, Sztukowska MN, Till M et al (2017) The Streptococcus gordonii adhesin CshA protein binds host fibronectin via a catchclamp mechanism. J Biol Chem 292:1538-1549. https://doi.org/ 10.1074/jbc.M116.760975

87. Cross BW, Ruhl S (2018) Glycan recognition at the saliva - oral microbiome interface. Cell Immunol 333:19-33. https://doi.org/ 10.1016/j.cellimm.2018.08.008

88. Thamadilok S, Roche-Hakansson H, Hakansson AP, Ruhl S (2016) Absence of capsule reveals glycan-mediated binding and recognition of salivary mucin Muc7 by Streptococcus pneumoniae. Mol Oral Microbiol 31:175-188. https://doi.org/10. 1016/j.physbeh.2017.03.040

89. Avilés-Reyes A, Miller JH, Lemos JA, Abranches J (2017) Collagen-binding proteins of Streptococcus mutans and related streptococci. Mol Oral Microbiol 32:89-106. https://doi.org/10. 1111/omi.12158

90. Nomura R, Ogaya Y, Nakano K (2016) Contribution of the collagen-binding proteins of Streptococcus mutans to bacterial colonization of inflamed dental pulp. PLoS One 11:e159613. https://doi.org/10.1371/journal.pone.0159613

91. Heller D, Helmerhorst EJ, Gower AC et al (2016) Microbial diversity in the early in vivo-formed dental biofilm. Appl Environ Microbiol 82:1881-1888. https://doi.org/10.1128/AEM.03984-15

92. Espinoza JL, Harkins DM, Torralba M et al (2018) Supragingival plaque microbiome ecology and functional potential in the context of health and disease. MBio 9:e01631-e01618. https://doi.org/10. 1128/mBio.01631-18

93. Koo H, Falsetta ML, Klein MI (2013) The exopolysaccharide matrix: a virulence determinant of cariogenic biofilm. J Dent Res 92:1065-1073. https://doi.org/10.1177/0022034513504218

94. Palmer RJ, Shah N, Valm A et al (2017) Interbacterial adhesion networks within early oral biofilms of single human hosts. Appl Environ Microbiol 83:e00407-e00417. https://doi.org/10.1128/ AEM.00407-17

95. Wen ZT, Yates D, Ahn SJ, Burne RA (2010) Biofilm formation and virulence expression by Streptococcus mutans are altered when grown in dual-species model. BMC Microbiol:10. https:// doi.org/10.1186/1471-2180-10-111

96. Shemesh M, Tam A, Aharoni R, Steinberg D (2010) Genetic adaptation of Streptococcus mutans during biofilm formation on different types of surfaces. BMC Microbiol 10:51. https://doi.org/ 10.1186/1471-2180-10-51

97. Diaz PI, Dupuy AK, Abusleme L et al (2012) Using high throughput sequencing to explore the biodiversity in oral bacterial communities. Mol Oral Microbiol 27:182-201. https://doi.org/10. 1037/a0032811.Child

98. Segata N, Haake SK, Mannon P et al (2012) Composition of the adult digestive tract bacterial microbiome based on seven mouth surfaces, tonsils, throat and stool samples. Genome Biol 13:R42. https://doi.org/10.1186/gb-2012-13-6-r42

99. Eren AM, Borisy GG, Huse SM, Mark Welch JL (2014) Oligotyping analysis of the human oral microbiome. Proc Natl Acad Sci U S A 111:E2875-E2884. https://doi.org/10.1073/ pnas. 1409644111

100. Lempel E, Tóth Á, Fábián T et al (2015) Retrospective evaluation of posterior direct composite restorations: 10-year findings. Dent Mater 31:115-122. https://doi.org/10.1016/j.dental.2014.11.001

101. Nedeljkovic I, Teughels W, De Munck J et al (2015) Is secondary caries with composites a material-based problem? Dent Mater 31: e247-e277. https://doi.org/10.1016/j.dental.2015.09.001 
102. Imazato S (2003) Antibacterial properties of resin composites and dentin bonding systems. Dent Mater 19:449-457. https://doi.org/ 10.1016/S0109-5641(02)00102-1

103. Leonhardt OJ, Dahlén G (1995) Bacterial colonization on titanium, hydroxyapatite, and amalgam surfaces in vivo. J Dent Res 74 : 1607-1612. https://doi.org/10.1177/00220345950740091701

104. Bourbia M, Ma D, Cvitkovitch DG et al (2013) Cariogenic bacteria degrade dental resin composites and adhesives. J Dent Res 92: 989-994. https://doi.org/10.1177/0022034513504436

105. Zhang N, Melo MAS, Weir MD et al (2016) Do dental resin composites accumulate more oral biofilms and plaque than amalgam and glass ionomer materials? Materials (Basel) 9:888. https:// doi.org/10.3390/ma9110888

106. Sousa RP, Zanin ICJ, Lima JPM et al (2009) In situ effects of restorative materials on dental biofilm and enamel demineralisation. J Dent 37:44-51. https://doi.org/10.1016/j. jdent.2008.08.009

107. Mo S, Bao W, Lai G et al (2010) The microfloral analysis of secondary caries biofilm around class I and class II composite and amalgam fillings. BMC Infect Dis 10:241. https://doi.org/10. 1186/1471-2334-10-241

108. Padovani GC, Fùcio SBP, Ambrosano GMB et al (2015) In situ bacterial accumulation on dental restorative materials. CLSM/ COMSTAT analysis. Am J Dent 28:3-8

109. Conrads G, Wendt LK, Hetrodt F et al (2019) Deep sequencing of biofilm microbiomes on dental composite materials. J Oral Microbiol 11:1617013. https://doi.org/10.1080/20002297.2019. 1617013

110. Chau NPT, Pandit S, Jung J-E et al (2016) Long-term anti-cariogenic biofilm activity of glass ionomers related to fluoride release. J Dent 47:34-40. https://doi.org/10.1016/j.jdent.2016.02.006

111. Mayanagi G, Igarashi K, Washio J et al (2014) Effect of fluoridereleasing restorative materials on bacteria-induced $\mathrm{pH}$ fall at the bacteria-material interface: an in vitro model study. J Dent 42:1520. https://doi.org/10.1016/j.jdent.2013.11.006

112. Miki S, Kitagawa H, Kitagawa R et al (2016) Antibacterial activity of resin composites containing surface pre-reacted glass-ionomer (S-PRG) filler. Dent Mater 32:1095-1102. https://doi.org/10. 1016/j.dental.2016.06.018

113. Wang S, Guo L, Seneviratne CJ et al (2014) Biofilm formation of salivary microbiota on dental restorative materials analyzed by denaturing gradient gel electrophoresis and sequencing. Dent Mater J 33:325-331. https://doi.org/10.4012/dmj.2013-152

114. Ma S, Imazato S, Chen JH et al (2012) Effects of a coating resin containing S-PRG filler to prevent demineralization of root surfaces. Dent Mater J 31:909-915. https://doi.org/10.4012/dmj. 2012-061

115. Kim KH, Loch C, Waddell JN et al (2017) Surface characteristics and biofilm development on selected dental ceramic materials. Int J Dent:2017. https://doi.org/10.1155/2017/7627945

116. Rashid H (2014) The effect of surface roughness on ceramics used in dentistry: a review of literature. Eur J Dent 8:571-579. https:// doi.org/10.4103/1305-7456.143646

117. Bremer F, Grade S, Kohorst P, Stiesch M (2011) In vivo biofilm formation on different dental ceramics. Quintessence Int 42:565574

118. Goodson JM, Shoher I, Imber S et al (2001) Reduced dental plaque accumulation on composite gold alloy margins. J Periodontal Res 36:252-259. https://doi.org/10.1034/j.16000765.2001.036004252.x

119. Auschill TM, Arweiler NB, Brecx M et al (2002) The effect of dental restorative materials on dental biofilm. Eur J Oral Sci 110: $48-53$

120. Ismail F, Eisenburger M, Grade S, Stiesch M (2016) In situ biofilm formation on titanium, gold alloy and zirconia abutment materials. Dentistry 6:400. https://doi.org/10.4172/2161-1122. 1000400

121. Dittmer MP, Hellemann CF, Grade S et al (2015) Comparative three-dimensional analysis of initial biofilm formation on three orthodontic bracket materials. Head Face Med 11:10. https://doi. org/10.1186/s13005-015-0062-0

122. Urushibara Y, Ohshima T, Sato M et al (2014) An analysis of the biofilms adhered to framework alloys using in vitro denture plaque models. Dent Mater J 33:402-414. https://doi.org/10.4012/dmj. 2013-325

123. Jordan RPC, Marsh L, Ayre WN et al (2016) An assessment of early colonisation of implant-abutment metal surfaces by single species and co-cultured bacterial periodontal pathogens. J Dent 53:64-72. https://doi.org/10.1016/j.jdent.2016.07.013

124. Souza JCM, Mota RRC, Sordi MB et al (2016) Biofilm formation on different materials used in oral rehabilitation. Braz Dent J 27: 141-147. https://doi.org/10.1590/0103-6440201600625

125. Gleiznys A, Zdanavičienė E, Žilinskas J (2015) Candida albicans importance to denture wearers. A literature review. Stomatologija 17:54-66

126. Morse DJ, Smith A, Wilson MJ et al (2019) Molecular community profiling of the bacterial microbiota associated with denturerelated stomatitis. Sci Rep 9:10228. https://doi.org/10.1038/ s41598-019-46494-0

127. O'Donnell LE, Alalwan HKA, Kean R et al (2017) Candida albicans biofilm heterogeneity does not influence denture stomatitis but strongly influences denture cleansing capacity. J Med Microbiol 66:54-60. https://doi.org/10.1099/jmm.0.000419

128. Korsch M, Walther W, Marten SM, Obst U (2014) Microbial analysis of biofilms on cement surfaces: an investigation in cement-associated peri-implantitis. J Appl Biomater Fundam Mater 12:70-80. https://doi.org/10.5301/jabfm.5000206

129. Korsch M, Marten SM, Dötsch A et al (2016) Effect of dental cements on peri-implant microbial community: comparison of the microbial communities inhabiting the peri-implant tissue when using different luting cements. Clin Oral Implants Res 27:e161e166. https://doi.org/10.1111/clr.12582

130. Korsch M, Marten SM, Walther W et al (2018) Impact of dental cement on the peri-implant biofilm-microbial comparison of two different cements in an in vivo observational study. Clin Implant Dent Relat Res 20:806-813. https://doi.org/10.1111/cid.12650

131. Cortes-Acha B, Figueiredo R, Blanc V et al (2019) Development and viability of biofilms grown on experimental abutments mimicking dental implants: an in vivo model. Med Oral Patol Oral y Cir Bucal 24:5511-5517. https://doi.org/10.4317/medoral.22868

132. Cortés-Acha B, Figueiredo R, Seminago R et al (2017) Microbiota analysis of biofilms on experimental abutments mimicking dental implants: an in vivo model. J Periodontol 88:1090-1104. https:// doi.org/10.1902/jop.2017.170051

133. Salvi GE, Cosgarea R, Sculean A (2017) Prevalence and mechanisms of peri-implant diseases. J Dent Res 96:31-37. https://doi. org/10.1177/0022034516667484

134. Kumar PS, Mason MR, Brooker MR, O’Brien K (2012) Pyrosequencing reveals unique microbial signatures associated with healthy and failing dental implants. J Clin Periodontol 39: 425-433. https://doi.org/10.1111/j.1600-051X.2012.01856.x

135. Zheng $\mathrm{H}, \mathrm{Xu} \mathrm{L}$, Wang $\mathrm{Z}$ et al (2015) Subgingival microbiome in patients with healthy and ailing dental implants. Sci Rep 5:1-11. https://doi.org/10.1038/srep10948

136. Sanz-Martin I, Doolittle-Hall J, Teles RP et al (2017) Exploring the microbiome of healthy and diseased peri-implant sites using Illumina sequencing. J Clin Periodontol 44:1274-1284. https:// doi.org/10.1111/jcpe. 12788

137. Shibli JA, Melo L, Ferrari DS et al (2008) Composition of supraand subgingival biofilm of subjects with healthy and diseased 
implants. Clin Oral Implants Res 19:975-982. https://doi.org/10. 1111/j.1600-0501.2008.01566.x

138. do Nascimento C, Pita MS, de Souza Santos E et al (2016) Microbiome of titanium and zirconia dental implants abutments. Dent Mater 32:93-101. https://doi.org/10.1016/j.dental.2015.10. 014

139. Do Nascimento C, Pita MS, Pedrazzi V et al (2013) In vivo evaluation of Candida spp. adhesion on titanium or zirconia abutment surfaces. Arch Oral Biol 58:853-861. https://doi.org/10.1016/j. archoralbio.2013.01.014

140. Raffaini FC, Freitas AR, Silva TSO et al (2018) Genome analysis and clinical implications of the bacterial communities in early biofilm formation on dental implants restored with titanium or zirconia abutments. Biofouling 34:173-182. https://doi.org/10. 1080/08927014.2017.1417396

141. do Nascimento C, Pita MS, Nogueira FH et al (2013) Bacterial adhesion on the titanium and zirconia abutment surfaces. Clin Oral Implants Res 25:337-343. https://doi.org/10.1111/clr.12093

142. Größner-Schreiber B, Teichmann J, Hannig M et al (2009) Modified implant surfaces show different biofilm compositions under in vivo conditions. Clin Oral Implants Res 20:817-826. https://doi.org/10.1111/j.1600-0501.2009.01729.x

143. de Freitas AR, de O Silva TS, Ribeiro RF et al (2018) Oral bacterial colonization on dental implants restored with titanium or zirconia abutments: 6-month follow-up. Clin Oral Investig 22:23352343. https://doi.org/10.1007/s00784-018-2334-0

144. Hao Y, Huang X, Zhou X et al (2018) Influence of dental prosthesis and restorative materials interface on oral biofilms. Int J Mol Sci 19:3157. https://doi.org/10.3390/ijms19103157

145. Souza JGS, Costa Oliveira BE, Bertolini M et al (2019) Titanium particles and ions favor dysbiosis in oral biofilms. J Periodont Res 00:1-9. https://doi.org/10.1111/jre.12711

146. Fretwurst T, Nelson K, Tarnow DP et al (2018) Is metal particle release associated with peri-implant bone destruction? An emerging concept. J Dent Res 97:259-265. https://doi.org/10.1177/ 0022034517740560

147. Hannig M (1999) Transmission electron microscopy of early plaque formation on dental materials in vivo. Eur J Oral Sci 107: 55-64. https://doi.org/10.1046/j.0909-8836.1999.eos107109.x

148. Lima EMCX, Koo H, Vacca Smith AM et al (2008) Adsorption of salivary and serum proteins, and bacterial adherence on titanium and zirconia ceramic surfaces. Clin Oral Implants Res 19:780 785. https://doi.org/10.1111/j.1600-0501.2008.01524.x

149. Hannig C, Wasser M, Becker K et al (2006) Influence of different restorative materials on lysozyme and amylase activity of the salivary pellicle in situ. J Biomed Mater Res A 79:963-973. https:// doi.org/10.1002/jbm.a

150. Hannig C, Huber K, Lambrichts I et al (2007) Detection of salivary alpha-amylase and lysozyme exposed on the pellicle formed in situ on different materials. J Biomed Mater Res A 83:98-103. https://doi.org/10.1002/jbm.a

151. Yoshida E, Hayakawa T (2013) Adsorption study of pellicle proteins to gold, silica and titanium by quartz crystal microbalance method. Dent Mater J 32:883-887. https://doi.org/10.4012/dmj. 2013-136

152. Pantaroto HN, Amorim KP, Matozinho Cordeiro J et al (2019) Proteome analysis of the salivary pellicle formed on titanium alloys containing niobium and zirconium. Biofouling 35:173-186. https://doi.org/10.1080/08927014.2019.1580360

153. Thomas RZ, Van Der Mei HC, Van Der Veen MH et al (2008) Bacterial composition and red fluorescence of plaque in relation to primary and secondary caries next to composite: an in situ study. Oral Microbiol Immunol 23:7-13. https://doi.org/10.1111/j.1399302X.2007.00381.x

154. Pogodin S, Hasan J, Baulin VA et al (2013) Biophysical model of bacterial cell interactions with nanopatterned cicada wing surfaces. Biophys J 104:835-840. https://doi.org/10.1016/j.bpj. 2012.12.046

155. Hannig M, Kriener L, Hoth-Hannig W et al (2007) Influence of nanocomposite surface coating on biofilm formation in situ. $\mathrm{J}$ Nanosci Nanotechnol 7:4642-4648

156. Jenny N, Naorem S, Naorem K, Singh PD (2017) Know about biocompatibility of dental materials : a review. Pyrex J Med Med Sci 4:33-43

157. Monsees TK (2016) Biocompatibility and anti-microbiological activity characterization of novel coatings for dental implants: a primer for non-biologists. Front Mater 3:1-6. https://doi.org/10. 3389/fmats.2016.00040

158. Wataha JC, Lockwood PE (1998) Release of elements from dental casting alloys into cell-culture medium over 10 months. Dent Mater 14:158-163. https://doi.org/10.1016/S0109-5641(98) 00023-2

159. Elshahawy W, Watanabe I (2014) Biocompatibility of dental alloys used in dental fixed prosthodontics. Tanta Dent J 11:150 159. https://doi.org/10.1016/j.tdj.2014.07.005

160. Sjogren G, Sletten G, DJE (2000) Cytotoxicity of dental alloys, metals, and ceramics assessed by Millipore. J Prosthet Dent 84 : 229-236

161. Yang HC, Pon LA (2003) Toxicity of metal ions used in dental alloys: a study in the yeast Saccharomyces cerevisiae. Drug Chem Toxicol 26:75-85. https://doi.org/10.1081/DCT-120020403

162. Fathi M, Mortazavi V (2004) A review on dental amalgam corrosion and its consequences. J Res Med Sci 9:42-51

163. Freire WP, Fook MVL, Barbosa EF et al (2015) Biocompatibility of dental restorative materials. Mater Sci Forum 805:19-25. https://doi.org/10.4028/www.scientific.net/MSF.805.19

164. Sidhu S, Nicholson J (2016) A review of glass-ionomer cements for clinical dentistry. J Funct Biomater 7:16. https://doi.org/10. 3390/jfb7030016

165. Priyadarsini S, Mukherjee S, Mishra M (2018) Nanoparticles used in dentistry: a review. J Oral Biol Craniofacial Res 8:58-67. https://doi.org/10.1016/j.jobcr.2017.12.004

166. Wang J, Wang L, Fan Y (2016) Adverse biological effect of TiO2 and hydroxyapatite nanoparticles used in bone repair and replacement. Int J Mol Sci 17:798. https://doi.org/10.3390/ijms17060798

167. Choi C-H, Hagvall SH, Wu BM et al (2007) Cell interaction with three-dimensional sharp-tip nanotopography. Biomaterials 28: 1672-1679. https://doi.org/10.1016/j.biomaterials.2006.11.031

168. Jang Y, Choi WT, Johnson CT et al (2018) Inhibition of bacterial adhesion on nanotextured stainless steel 316 by electrochemical etching. ACS Biomater Sci Eng 4:90-97. https://doi.org/10.1021/ acsbiomaterials. $7 \mathrm{~b} 00544$

169. Cheng Y, Feng G, Moraru CI (2019) Micro- and nanotopography sensitive bacterial attachment mechanisms: a review. Front Microbiol 10:191. https://doi.org/10.3389/fmicb.2019.00191

170. Quirynen M, Bollen CML (1995) The influence of surface roughness and surface-free energy on supra- and subgingival plaque formation in man. J Clin Periodontol 22:1-14

171. Fröjd V, Chávez de Paz L, Andersson M et al (2011) In situ analysis of multispecies biofilm formation on customized titanium surfaces. Mol Oral Microbiol 26:241-252. https://doi.org/10. 1111/j.2041-1014.2011.00610.x

172. Xing R, Lyngstadaas SP, Ellingsen JE et al (2015) The influence of surface nanoroughness, texture and chemistry of TiZr implant abutment on oral biofilm accumulation. Clin Oral Implants Res 26:649-656. https://doi.org/10.1111/clr.12354

173. Bürgers R, Gerlach T, Hahnel S et al (2010) In vivo and in vitro biofilm formation on two different titanium implant surfaces. Clin Oral Implants Res 21:156-164. https://doi.org/10.1111/j.16000501.2009.01815.x

174. Al-Ahmad A, Wiedmann-Al-Ahmad M, Faust J et al (2010) Biofilm formation and composition on different implant materials 
in vivo. J Biomed Mater Res B Appl Biomater 95B:101-109. https://doi.org/10.1002/jbm.b.31688

175. de Melo F, do Nascimento C, Souza DO, de Albuquerque RF (2017) Identification of oral bacteria on titanium implant surfaces by $16 \mathrm{~S}$ rDNA sequencing. Clin Oral Implants Res 28:697-703. https://doi.org/10.1111/clr.12865

176. Ribeiro CF, Cogo-Müller K, Franco GC et al (2016) Initial oral biofilm formation on titanium implants with different surface treatments: an in vivo study. Arch Oral Biol 69:33-39. https://doi.org/ 10.1016/j.archoralbio.2016.05.006

177. Conserva E, Generali L, Bandieri A et al (2018) Plaque accumulation on titanium disks with different surface treatments: an in vivo investigation. Odontology 106:145-153. https://doi.org/ 10.1007/s10266-017-0317-2

178. Al-Ahmad A, Karygianni L, Wartenhorst MS et al (2016) Bacterial adhesion and biofilm formation on yttriastabilized, tetragonal zirconia and titanium oral implant materials with low surface roughness - an in situ study. J Med Microbiol 65:596604. https://doi.org/10.1099/jmm.0.000267

179. Bevilacqua L, Milan A, Del Lupo V et al (2018) Biofilms developed on dental implant titanium surfaces with different roughness: comparison between in vitro and in vivo studies. Curr Microbiol 75:766-772. https://doi.org/10.1007/s00284-018-1446-8

180. Bollen CM, Lambrechts P, Quirynen M (1997) Comparison of surface roughness of oral hard materials to the threshold surface roughness for bacterial plaque retention: a review of the literature. Dent Mater 13:258-269

181. Quirynen M, Bollen CM, Papaioannou W et al (1996) The influence of titanium abutment surface roughness on plaque accumulation and gingivitis: short-term observations. Int J Oral Maxillofac Implants 11:169-178

182. Taha M, El-Fallal A, Degla H (2016) In vitro and in vivo biofilm adhesion to esthetic coated arch wires and its correlation with surface roughness. Angle Orthod 86:285-291. https://doi.org/10. 2319/122814-947.1

183. Gadelmawla ES, Koura MM, Maksoud TMA et al (2002) Roughness parameters. J Mater Process Technol 123:133-145. https://doi.org/10.1016/s0924-0136(02)00060-2

184. Jumelle C, Hamri A, Egaud G et al (2017) Comparison of four methods of surface roughness assessment of corneal stromal bed after lamellar cutting. Biomed Opt Express 8:4974. https://doi.org/ 10.1364/boe.8.004974

185. Duparré A, Ferre-Borrull J, Gliech S et al (2002) Surface characterization techniques for determining the root-mean-square roughness and power spectral densities of optical components. Appl Opt 41:154. https://doi.org/10.1364/ao.41.000154

186. Young PL, Brackbill TP, Kandlikar SG (2009) Comparison of roughness parameters for various microchannel surfaces in single-phase flow applications. Heat Transf Eng 30:78-90. https://doi.org/10.1080/01457630802293464

187. Rizzello L, Galeone A, Vecchio G et al (2012) Molecular response of Escherichia coli adhering onto nanoscale topography. Nanoscale Res Lett 7:575. https://doi.org/10.1186/1556-276X-7575

188. Rizzello L, Sorce B, Sabella S et al (2011) Impact of nanoscale topography on genomics and proteomics of adherent bacteria. ACS Nano 5:1865-1876. https://doi.org/10.1021/nn102692m

189. Rzhepishevska O, Hakobyan S, Ruhal R et al (2013) The surface charge of anti-bacterial coatings alters motility and biofilm architecture. Biomater Sci 1:589. https://doi.org/10.1039/c3bm00197k

190. Kiremitci-Gumusderelioglu M, Peșmen A (1996) Microbial adhesion to ionogenic PHEMA, PU PP implants. Biomaterials 17:443449. https://doi.org/10.1016/0142-9612(96)89662-1

191. Yuan Y, Hays MP, Hardwidge PR, Kim J (2017) Surface characteristics influencing bacterial adhesion to polymeric substrates. RSC Adv 7:14254-14261. https://doi.org/10.1039/c7ra01571b
192. Wassmann T, Kreis S, Behr M, Buergers R (2017) The influence of surface texture and wettability on initial bacterial adhesion on titanium and zirconium oxide dental implants. Int J Implant Dent 3. https://doi.org/10.1186/s40729-017-0093-3

193. Dou XQ, Zhang D, Feng C, Jiang L (2015) Bioinspired hierarchical surface structures with tunable wettability for regulating bacteria adhesion. ACS Nano 9:10664-10672. https://doi.org/10. 1021/acsnano.5b04231

194. Oliveira AS, Kaizer MR, Azevedo MS et al (2015) (Super)hydrophobic coating of orthodontic dental devices and reduction of early oral biofilm retention. Biomed Mater 10: 065004. https://doi.org/10.1088/1748-6041/10/6/065004

195. Elter C, Heuer W, Demling A et al (2011) Comparative analysis of biofilm formation on dental implant abutments with respect to supra- and subgingival areas: polytetrafluoroethylene versus titanium. Int J Prosthodont 24:373-375

196. Demling A, Elter C, Heidenblut $\mathrm{T}$ et al (2010) Reduction of biofilm on orthodontic brackets with the use of a polytetrafluoroethylene coating. Eur J Orthod 32:414-418. https://oi.org/10.1093/ejo/cjp142

197. Ensikat HJ, Ditsche-Kuru P, Neinhuis C, Barthlott W (2011) Superhydrophobicity in perfection: the outstanding properties of the lotus leaf. Beilstein J Nanotechnol 2:152-161. https://doi.org/ 10.3762/bjnano.2.19

198. Cheng YT, Rodak DE, Wong CA, Hayden CA (2006) Effects of micro- and nano-structures on the self-cleaning behaviour of lotus leaves. Nanotechnology 17:1359-1362. https://doi.org/10.1088/ 0957-4484/17/5/032

199. Hizal F, Rungraeng N, Lee J et al (2017) Nanoengineered superhydrophobic surfaces of aluminum with extremely low bacterial adhesivity. ACS Appl Mater Interfaces 9:12118-12129. https://doi.org/10.1021/acsami.7b01322

200. Morán G, Ramos-Chagas G, Hugelier S et al (2018) Superhydrophobic polypyrene films to prevent: Staphylococcus aureus and Pseudomonas aeruginosa biofilm adhesion on surfaces: high efficiency deciphered by fluorescence microscopy. Photochem Photobiol Sci 17:1023-1035. https://doi.org/10. 1039/c8pp00043c

201. Lee M, Kwon J, Jiang HB et al (2019) The antibacterial effect of non-thermal atmospheric pressure plasma treatment of titanium surfaces according to the bacterial wall structure. Sci Rep 9:113. https://doi.org/10.1038/s41598-019-39414-9

202. Hwang GB, Page K, Patir A et al (2018) The anti-biofouling properties of superhydrophobic surfaces are short-lived. ACS Nano 12:6050-6058. https://doi.org/10.1021/acsnano.8b02293

203. Sousa C, Rodrigues D, Oliveira R et al (2011) Superhydrophobic poly(L-lactic acid) surface as potential bacterial colonization substrate. AMB Express 1:34. https://doi.org/10.1186/2191-0855-134

204. Covarrubias C, Trepiana D, Corral C (2018) Synthesis of hybrid copper-chitosan nanoparticles with antibacterial activity against cariogenic Streptococcus mutans. Dent Mater J 37:379-384. https://doi.org/10.4012/dmj.2017-195

205. Farhoudian S, Yadollahi M, Namazi H (2016) Facile synthesis of antibacterial chitosan/ $\mathrm{CuO}$ bio-nanocomposite hydrogel beads. Int J Biol Macromol 82:837-843. https://doi.org/10.1016/j.ijbiomac. 2015.10.018

206. Sanpui P, Murugadoss A, Prasad PVD et al (2008) The antibacterial properties of a novel chitosan-Ag-nanoparticle composite. Int J Food Microbiol 124:142-146. https://doi.org/10.1016/j. ijfoodmicro.2008.03.004

207. González J, Covarrubias C, Cádiz M et al (2016) Design of antimicrobial release systems based on chitosan and copper nanoparticles for localized periodontal therapy. J Dent Oral Disord 2:1035

208. Memarzadeh K, Sharili AS, Huang J et al (2015) Nanoparticulate zinc oxide as a coating material for orthopedic and dental implants. 
J Biomed Mater Res A 103:981-989. https://doi.org/10.1002/jbm. a.35241

209. Arakha M, Pal S, Samantarrai D et al (2015) Antimicrobial activity of iron oxide nanoparticle upon modulation of nanoparticlebacteria interface. Sci Rep 5:14813. https://doi.org/10.1038/ srep14813

210. Stankic S, Suman S, Haque F, Vidic J (2016) Pure and multi metal oxide nanoparticles: synthesis, antibacterial and cytotoxic properties. J Nanobiotechnology 14:73. https://doi.org/10.1186/s12951016-0225-6

211. Chatzistavrou X, Lefkelidou A, Papadopoulou L et al (2018) Bactericidal and bioactive dental composites. Front Physiol 9: 103. https://doi.org/10.3389/fphys.2018.00103

212. Jin J, Zhang L, Shi M et al (2017) Ti-GO-Ag nanocomposite: the effect of content level on the antimicrobial activity and cytotoxicity. Int J Nanomed 12:4209-4224. https://doi.org/10.2147/IJN. $\mathrm{S} 134843$

213. Mangal U, Kim J-Y, Seo J-Y et al (2019) Novel poly (methyl methacrylate) containing nanodiamond to improve the mechanical properties and fungal resistance. Materials (Basel) 12:3438

214. Acosta LD, Pérez-Camacho O, Acosta R et al (2019) Reduction of Candida albicans biofilm formation by coating polymethyl methacrylate denture bases with a photopolymerized film. J Prosthet Dent. https://doi.org/10.1016/j.prosdent.2019.08.003

215. Zhang Y, Chen YY, Huang L et al (2017) The antifungal effects and mechanical properties of silver bromide/cationic polymer nano-composite-modified poly-methyl methacrylate-based dental resin. Sci Rep 7:1547. https://doi.org/10.1038/s41598-017-01686-

216. Feng J, Cheng L, Zhou X et al (2015) In situ antibiofilm effect of glass-ionomer cement containing dimethylaminododecyl methacrylate. Dent Mater 31:992-1002. https://doi.org/10.1016/j.dental. 2015.05.005

217. Feng J, Cheng L, Zhou X et al (2019) Effects of water aging on the mechanical and anti-biofilm properties of glass-ionomer cement containing dimethylaminododecyl methacrylate. Dent Mater 35: 434-443. https://doi.org/10.1016/j.dental.2018.12.003

218. Duque C, Aida KL, Pereira JA et al (2017) glass-ionomer cement containing chlorhexidine for atraumatic restorative treatment. J Appl Oral Sci 81:541-550

219. Frencken JE, Imazato S, Toi C et al (2007) Antibacterial effect of chlorhexidine-containing glass ionomer cement in vivo: a pilot study. Caries Res 41:102-107. https://doi.org/10.1159/ 000098042

220. Rupf S, Balkenhol M, Sahrhage TO et al (2012) Biofilm inhibition by an experimental dental resin composite containing octenidine dihydrochloride. Dent Mater 28:974-984. https://doi.org/10.1016/ j.dental.2012.04.034

221. Mellegård H, Strand SP, Christensen BE et al (2011) Antibacterial activity of chemically defined chitosans: influence of molecular weight, degree of acetylation and test organism. Int J Food Microbiol 148:48-54. https://doi.org/10.1016/j.ijfoodmicro.2011. 04.023

222. Stenhagen ISR, Rukke HV, Dragland IS, Kopperud HM (2019) Effect of methacrylated chitosan incorporated in experimental composite and adhesive on mechanical properties and biofilm formation. Eur J Oral Sci 127:81-88. https://doi.org/10.1111/eos. 12584

223. Mahmoud MY, Steinbach-Rankins JM, Demuth DR (2019) Functional assessment of peptide-modified PLGA nanoparticles against oral biofilms in a murine model of periodontitis. J Control Release 297:3-13. https://doi.org/10.1016/j.jconrel.2019.01.036

224. Mahmoud MY, Demuth DR, Steinbach-Rankins JM (2018) BARencapsulated nanoparticles for the inhibition and disruption of Porphyromonas gingivalis-Streptococcus gordonii biofilms. J
Nanobiotechnology 16:1-12. https://doi.org/10.1186/s12951018-0396-4

225. Xu LC, Wo Y, Meyerhoff ME, Siedlecki CA (2017) Inhibition of bacterial adhesion and biofilm formation by dual functional textured and nitric oxide releasing surfaces. Acta Biomater 51:53-65. https://doi.org/10.1016/j.actbio.2017.01.030

226. Sundheim G, Langsrud S, Heir E, Holck AL (1998) Bacterial resistance to disinfectants containing quaternary ammonium compounds. Int Biodeterior Biodegrad 41:235-239. https://doi.org/10. 1016/S0964-8305(98)00027-4

227. Kwaśniewska D, Chen YL, Wieczorek D (2020) Biological activity of quaternary ammonium salts and their derivatives. Pathogens 9:459. https://doi.org/10.3390/pathogens9060459

228. Whitehead KA, Colligon J, Verran J (2005) Retention of microbial cells in substratum surface features of micrometer and submicrometer dimensions. Colloids Surfaces B Biointerfaces 41: 129-138. https://doi.org/10.1016/j.colsurfb.2004.11.010

229. Helbig R, Günther D, Friedrichs J et al (2016) The impact of structure dimensions on initial bacterial adhesion. Biomater Sci 4:1074-1078. https://doi.org/10.1039/C6BM00078A

230. Hochbaum AI, Aizenberg J (2010) Bacteria pattern spontaneously on periodic nanostructure arrays. Nano Lett 10:3717-3721. https://doi.org/10.1021/nl102290k

231. Valle J, Burgui S, Langheinrich D et al (2015) Evaluation of surface microtopography engineered by direct laser interference for bacterial anti-biofouling. Macromol Biosci 15:1060-1069. https://doi.org/10.1002/mabi.201500107

232. Roessler F, Lasagni AF (2018) Protecting sub-micrometer surface features in polymers from mechanical damage using hierarchical patterns. J Laser Micro Nanoeng 13:68-75. https://doi.org/10. 2961/jlmn.2018.02.0004

233. Jung YC, Bhushan B (2009) Mechanically durable carbon nanotube - composite hierarchical structures with superhydrophobicity, self-cleaning, and low-drag. ACS Nano 3:4155-4163. https://doi. org/10.1021/nn901509r

234. Groten J, Rühe J (2013) Surfaces with combined microscale and nanoscale structures: a route to mechanically stable superhydrophobic surfaces? Langmuir 29:3765-3772. https:// doi.org/10.1021/la304641q

235. Tebbs SE, Sawyer A, Elliott TS (1994) Influence of surface morphology on in vitro bacterial adherence to central venous catheters. Br J Anaesth 72:587-591

236. Flint SH, Brooks JD, Bremer PJ (2000) Properties of the stainless steel substrate, influencing the adhesion of thermo-resistant streptococci. J Food Eng 43:235-242. https://doi.org/10.1016/S02608774(99)00157-0

237. Díaz C, Schilardi PL, Salvarezza RC, de Mele MFL (2007) Nano/ microscale order affects the early stages of biofilm formation on metal surfaces. Langmuir 23:11206-11210. https://doi.org/10. 1021/la700650q

238. Verran J, Packer A, Kelly P, Whitehead KA (2010) The retention of bacteria on hygienic surfaces presenting scratches of microbial dimensions. Lett Appl Microbiol 50:258-263. https://doi.org/10. 1111/j.1472-765X.2009.02784.X

239. Ihnen AC, Lee J-H, Lee WY (2010) Effects of disordered hemispherical micropatterns on Staphylococcus epidermidis biofilm formation. Colloids Surf B Biointerfaces 75:601-607. https://doi. org/10.1016/j.colsurfb.2009.10.014

240. Wu Y, Zitelli JP, TenHuisen KS et al (2011) Differential response of staphylococci and osteoblasts to varying titanium surface roughness. Biomaterials 32:951-960. https://doi.org/10.1016/j. biomaterials.2010.10.001

241. Hannig C, Helbig R, Hilsenbeck J et al (2018) Impact of the springtail's cuticle nanotopography on bioadhesion and biofilm formation in vitro and in the oral cavity. R Soc Open Sci 5. https://doi.org/10.1098/rsos.171742 
242. Romano JM, Ahmed R, Garcia-Giron A et al (2019) Subwavelength direct laser nanopatterning via microparticle arrays for functionalizing metallic surfaces. J Micro Nano Manuf 7: 1-11. https://doi.org/10.1115/1.4042964

243. Graham M, Cady N (2014) Nano and microscale topographies for the prevention of bacterial surface fouling. Coatings 4:37-59. https://doi.org/10.3390/coatings4010037

244. Whitehead KA, Verran J (2006) The effect of surface topography on the retention of microorganisms. Trans IChemE Part C 84:253259. https://doi.org/10.1205/fbp06035

245. Kerr A, Cowling MJ (2003) The effects of surface topography on the accumulation of biofouling. Philos Mag 83:2779-2795. https://doi.org/10.1080/1478643031000148451

246. Ivanova EP, Truong VK, Wang JY et al (2010) Impact of nanoscale roughness of titanium thin film surfaces on bacterial retention. Langmuir 26:1973-1982. https://doi.org/10.1021/ La902623c

247. Mitik-Dineva N, Wang J, Truong VK et al (2009) Escherichia coli, Pseudomonas aeruginosa, and Staphylococcus aureus attachment patterns on glass surfaces with nanoscale roughness. Curr Microbiol 58:268-273. https://doi.org/10.1007/s00284-0089320-8

248. Singh AV, Vyas V, Patil R et al (2011) Quantitative characterization of the influence of the nanoscale morphology of nanostructured surfaces on bacterial adhesion and biofilm formation. PLoS One 6:e25029. https://doi.org/10.1371/journal.pone.0025029

249. Satriano C, Messina GML, Carnazza S et al (2006) Bacterial adhesion onto nanopatterned polymer surfaces. Mater Sci Eng C Biomimetic Supramol Syst 26:942-946. https://doi.org/10.1016/ j.msec.2005.09.096

250. Park MR, Banks MK, Applegate B, Webster TJ (2008) Influence of nanophase titania topography on bacterial attachment and metabolism. Int J Nanomed 3:497-504. https://doi.org/10.2147/IJN. S4399

251. Lundqvist M, Sethson I, Jonsson BH (2004) Protein adsorption onto silica nanoparticles: conformational changes depend on the particles' curvature and the protein stability. Langmuir 20:10639 10647. https://doi.org/10.1021/la0484725

252. Roach P, Farrar D, Perry CC (2006) Surface tailoring for controlled protein adsorption: effect of topography at the nanometer scale and chemistry. J Am Chem Soc 128:3939-3945. https://doi. org/10.1021/ja056278e

253. Anselme K, Davidson P, Popa AM et al (2010) The interaction of cells and bacteria with surfaces structured at the nanometre scale. Acta Biomater 6:3824-3846. https://doi.org/10.1016/j.actbio. 2010.04.001

254. Bazaka K, Crawford RJ, Ivanova EP (2011) Do bacteria differentiate between degrees of nanoscale surface roughness? Biotechnol J 6:1103-1114. https://doi.org/10.1002/biot.201100027

255. Lejars M, Margaillan A, Bressy C (2012) Fouling release coatings: a nontoxic alternative to biocidal antifouling coatings. Chem Rev 112:4347-4390. https://doi.org/10.1021/cr200350v

256. Chen S, Li L, Zhao C, Zheng J (2010) Surface hydration: principles and applications toward low-fouling/nonfouling biomaterials. Polymer (Guildf) 51:5283-5293. https://doi.org/10.1016/j. polymer.2010.08.022

257. Baier RE (2006) Surface behaviour of biomaterials: the theta surface for biocompatibility. J Mater Sci Mater Med 17:1057-1062

258. Epstein AK, Hochbaum AI, Kim P, Aizenberg J (2011) Control of bacterial biofilm growth on surfaces by nanostructural mechanics and geometry. Nanotechnology 22:494007-494014. Artn 494007. https://doi.org/10.1088/0957-4484/22/49/494007

259. Song F, Ren D (2014) Stiffness of cross-linked poly(dimethylsiloxane) affects bacterial adhesion and antibiotic susceptibility of attached cells. Langmuir 30:10354-10362
260. Beachey EH (1981) Bacterial adherence: adhesin-receptor interactions mediating the attachment of bacteria to mucosal surfaces. J Infect Dis 143:325-345. https://doi.org/10.1093/infdis/143.3.325

261. Gibbons RJ (1989) Bacterial adhesion to oral tissue: a model for infectious diseases. J Dent Res 68:750-760. https://doi.org/10. 1177/00220345890680050101

262. Herrmann M, Vaudaux PE, Pittet D et al (1988) Fibronectin, fibrinogen, and laminin act as mediators of adherence of clinical staphylococcal isolates to foreign material. J Infect Dis 158:693701

263. Fröman G, Switalski LM, Speziale P, Höök M (1987) Isolation and characterization of a fibronectin receptor from Staphylococcus aureus. J Biol Chem 262:6564-6571

264. Guégan C, Garderes J, Le Pennec G et al (2014) Alteration of bacterial adhesion induced by the substrate stiffness. Colloids Surfaces B Biointerfaces 114:193-200. https://doi.org/10.1016/j. colsurfb.2013.10.010

265. Jaggessar A, Shahali H, Mathew A, Yarlagadda PKDV (2017) Bio-mimicking nano and micro-structured surface fabrication for antibacterial properties in medical implants. J Nanobiotechnol 15: 1-20. https://doi.org/10.1186/s12951-017-0306-1

266. McHale G, Newton MI, Shirtcliffe NJ (2009) Dynamic wetting and spreading and the role of topography. J Phys Condens Matter 21:464122. https://doi.org/10.1088/0953-8984/21/46/464122

267. Wagner T, Neinhuis C, Barthlott W (1996) Wettability and contaminability of insect wings as a function of their surface sculptures. Acta Zool 77:213-225. https://doi.org/10.1111/j. 1463-6395.1996.tb01265.x

268. Barthlott W, Neinhuis C (1997) Purity of the sacred lotus, or escape from contamination in biological surfaces. Planta 202:1-8

269. Helbig R, Nickerl J, Neinhuis C, Werner C (2011) Smart skin patterns protect springtails. PLoS One 6:e25105(pp1-6). https:/ doi.org/10.1371/journal.pone.0025105

270. Hensel R, Finn A, Helbig R et al (2013) Biologically inspired omniphobic surfaces by reverse imprint lithography. Adv Mater 26:2029-2033. https://doi.org/10.1002/adma.201305408

271. Hensel R, Helbig R, Aland S et al (2013) Wetting resistance at its topographical limit: the benefit of mushroom and serif $\mathrm{T}$ structures. Langmuir 29:1100-1112. https://doi.org/10.1021/ la304179b

272. Epstein AK, Pokroy B, Seminara A, Aizenberg J (2011) Bacterial biofilm shows persistent resistance to liquid wetting and gas penetration. Proc Natl Acad Sci U S A 108:995-1000. https://doi.org/ 10.1073/pnas. 1011033108

273. Bohn HF, Federle W (2004) Insect aquaplaning: Nepenthes pitcher plants capture prey with the peristome, a fully wettable waterlubricated anisotropic surface. Proc Natl Acad Sci 101:1413814143. https://doi.org/10.1073/pnas.0405885101

274. Kelleher SM, Habimana O, Lawler J, et al (2015) Cicada wing surface topography: an investigation into the bactericidal properties of nanostructural features. ACS Appl Mater Interfaces acsami.5b08309. https://doi.org/10.1021/acsami.5b08309

275. Diu T, Faruqui N, Sjöström T et al (2014) Cicada-inspired cellinstructive nanopatterned arrays. Sci Rep 4:7122. https://doi.org/ 10.1038/srep07122

276. Ivanova EP, Hasan J, Webb HK et al (2013) Bactericidal activity of black silicon. Nat Commun 4:1-7. https://doi.org/10.1038/ ncomms 3838

277. Li X (2015) Bactericidal mechanism of nanopatterned surfaces. Phys Chem Chem Phys 18:1311-1316. https://doi.org/10.1039/ c5cp05646b

278. Bandara CD, Singh S, Afara IO et al (2017) Bactericidal effects of natural nanotopography of dragonfly wing on Escherichia coli. ACS Appl Mater Interfaces 9:6746-6760. https://doi.org/10. 1021/acsami.6b13666 
279. Hasan J, Raj S, Yadav L, Chatterjee K (2015) Engineering a nanostructured "super surface" with superhydrophobic and superkilling properties. RSC Adv 5:44953-44959. https://doi.org/10.1039/ c5ra05206h

280. Fisher LE, Yang Y, Yuen M-F et al (2016) Bactericidal activity of biomimetic diamond nanocone surfaces. Biointerphases 11: 011014. https://doi.org/10.1116/1.4944062

281. Feng G, Cheng Y, Wang SY et al (2015) Bacterial attachment and biofilm formation on surfaces are reduced by small-diameter nanoscale pores: how small is small enough? npj Biofilms Microbiomes 1:15022. https://doi.org/10.1038/npjbiofilms.2015. 22

282. Feng G, Cheng Y, Wang SY et al (2014) Alumina surfaces with nanoscale topography reduce attachment and biofilm formation by Escherichia coli and Listeria spp. Biofouling 30:1253-1268. https://doi.org/10.1080/08927014.2014.976561

283. Bierbaum S, Mulansky S, Bognár E et al (2018) Osteogenic nanostructured titanium surfaces with antibacterial properties under conditions that mimic the dynamic situation in the oral cavity. Biomater Sci 6:1390-1402. https://doi.org/10.1039/c8bm00177d

284. Ionescu AC, Brambilla E, Azzola F et al (2018) Laser microtextured titanium implant surfaces reduce in vitro and in situ oral biofilm formation. PLoS One 13:e0202262. https://doi.org/ 10.1371/journal.pone.0202262

285. Miao X, Wang D, Xu L et al (2017) The response of human osteoblasts, epithelial cells, fibroblasts, macrophages and oral bacteria to nanostructured titanium surfaces: a systematic study. Int J Nanomed 12:1415-1430. https://doi.org/10.2147/IJN.S126760

286. Ferraris S, Cochis A, Cazzola M et al (2019) Cytocompatible and anti-bacterial adhesion nanotextured titanium oxide layer on titanium surfaces for dental and orthopedic implants. Front Bioeng Biotechnol 7:103. https://doi.org/10.3389/fbioe.2019.00103

287. Moyano DF, Saha K, Prakash G et al (2014) Fabrication of corona-free nanoparticles with tunable hydrophobicity. ACS Nano 8:6748-6755. https://doi.org/10.1021/nn5006478

288. Krause JE, Brault ND, Li Y et al (2011) Photoiniferter-mediated polymerization of zwitterionic carboxybetaine monomers for lowfouling and functionalizable surface coatings. Macromolecules 44:9213-9220. https://doi.org/10.1021/ma202007h

289. Carr LR, Zhou Y, Krause JE et al (2011) Uniform zwitterionic polymer hydrogels with a nonfouling and functionalizable crosslinker using photopolymerization. Biomaterials 32:68936899. https://doi.org/10.1016/j.biomaterials.2011.06.006

290. Chen S, Liu L, Jiang S (2006) Strong resistance of oligo(phosphorylcholine) self-assembled monolayers to protein adsorption. Langmuir 22:2418-2421. https://doi.org/10.1021/ la052851w
291. Lewis AL (2000) Phosphorylcholine-based polymers and their use in the prevention of biofouling. Colloids Surfaces B Biointerfaces 18:261-275. https://doi.org/10.1016/S0927-7765(99)00152-6

292. Youngblood JP, Andruzzi L, Ober CK et al (2003) Coatings based on side-chain ether-linked poly(ethylene glycol) and fluorocarbon polymers for the control of marine biofouling. Biofouling 19(Suppl):91-98. https://doi.org/10.1080/0892701021000053381

293. Kirillova A, Marschelke C, Friedrichs J et al (2016) Hybrid hairy Janus particles as building blocks for antibiofouling surfaces. ACS Appl Mater Interfaces 8:32591-32603. https://doi.org/10.1021/ acsami.6b10588

294. Aggarwal N, Lawson K, Kershaw M et al (2009) Protein adsorption on heterogeneous surfaces. Appl Phys Lett 94:1-4. https:// doi.org/10.1063/1.3078397

295. Takahara A, Hara Y, Kojio K, Kajiyama T (2002) Plasma protein adsorption behavior onto the surface of phase-separated organosilane monolayers on the basis of scanning force microscopy. Colloids Surfaces 23:141-152

296. Fang JY, Knobler CM (1996) Phase-separated two-component self-assembled organosilane monolayers and their use in selective adsorption of a protein. Langmuir 12:1368-1374

297. Wong SY, Han L, Timachova K et al (2012) Drastically lowered protein adsorption on microbicidal hydrophobic/hydrophilic polyelectrolyte multilayers. Biomacromolecules 13:719-726. https:// doi.org/10.1021/bm201637e

298. Jackson AM, Myerson JW, Stellacci F (2004) Spontaneous assembly of subnanometre-ordered domains in the ligand shell of monolayer-protected nanoparticles. Nat Mater 3:330-336. https:// doi.org/10.1038/nmat1116

299. Baxamusa SH, Gleason KK (2009) Random copolymer films with molecular-scale compositional heterogeneities that interfere with protein adsorption. Adv Funct Mater 19:3489-3496. https://doi. org/10.1002/adfm.200900943

300. Hung A, Mwenifumbo S, Mager M et al (2011) Ordering surfaces on the nanoscale: implications for protein adsorption. J Am Chem Soc 133:1438-1450. https://doi.org/10.1021/ja108285u

301. Paterlini TT, Nogueira LFB, Tovani CB et al (2017) The role played by modified bioinspired surfaces in interfacial properties of biomaterials. Biophys Rev 9:683-698. https://doi.org/10.1007/ s12551-017-0306-2

302. Naha PC, Liu Y, Hwang G, et al (2019) Dextran coated iron oxide nanoparticles as biomimetic catalysts for localized and $\mathrm{pH}$ activated biofilm disruption. ACS Nano acsnano.8b08702. https://doi.org/10.1021/acsnano.8b08702

Publisher's note Springer Nature remains neutral with regard to jurisdictional claims in published maps and institutional affiliations. 